\title{
Las formas kársticas del Macizo de las Ubiñas (Montañas Cantábricas)
}

\author{
Karst features in Las Ubiñas Massif (Cantabrian \\ Mountains)
}

\author{
David GALLINAR CAÑEDO*, Jesús RUIZ-FERNÁNDEZ, Cristina GARCÍA- \\ HERNÁNDEZ \\ Departamento de Geografía, Universidad de Oviedo, Oviedo/Uviéu, Asturias, España \\ *Contacto: gallinardavid@uniovi.es
}

https://doi.org/10.17979/cadlaxe.2021.43.0.8858

recibido: 23/12/2021 aceptado: 31/12/2021

\begin{abstract}
Las Ubiñas is one of the most outstanding limestone massifs in the Cantabrian Mountains. Its altitude and its climatic conditions (with heavy winter snowfalls in the highest sectors), favor karstification, but there are no specific studies to date. This research, based on field work and geomorphological mapping, examines the spatial distribution of karst features and processes, their altitudinal gradation, as well as their interferences with other landforms (especially with glacial and periglacial landforms). The results suggest that the karst has evolved through a succession of three stages (preglacial, glacial and postglacial), in which both climatic conditions and the main geomorphological processes have changed. At present, we differentiate three karstic areas according to the altitudinal gradient: low-altitude karst (below 1,700 m); karstic desert, and the nival karst area (above 1,700 m). The Massif is home to a great profusion of exokarstic landforms and an extensive endokarstic system network, evidencing an important influence and interdependence between karst features and processes, and Quaternary glaciers and the present-day periglacial and nival morphodynamics.
\end{abstract}

Keywords: nival karst, glaciokarst, Las Ubiñas Massif, Cantabrian Mountains

\section{Resumen}

El Macizo de Las Ubiñas, conformado en parte por un potente armazón calcáreo, constituye uno de los conjuntos altimontanos más destacados de las Montañas Cantábricas. Su desarrollo altitudinal y condiciones climáticas, con elevadas precipitaciones en forma de nieve, favorecen un notable desarrollo del karst sobre el que, sin embargo, hasta la fecha no existen estudios específicos. Esta investigación, basada en el trabajo de campo y la elaboración de cartografía 
geomorfológica, ha estudiado la distribución espacial de las formas y procesos kársticos, su gradación altitudinal, así como sus interferencias con otras formas de relieve, especialmente las derivadas del glaciarismo cuaternario y el periglaciarismo. Los resultados sugieren que el karst de Las Ubiñas se ha conformado a través de una sucesión de tres etapas (preglaciar, glaciar y postglaciar), en las que las condiciones climáticas y los procesos dominantes han sido cambiantes. En la actualidad, en función de la altitud, diferenciamos tres áreas kársticas: franja kárstica inferior, por debajo de 1.700 metros, con limitada influencia nival; el área de desierto kárstico, y franja de karst nival a partir de 1.700 metros. El Macizo alberga una gran profusión de macroformas, mesoformas y microformas exokársticas y una extensa red de conductos endokársticos, evidenciándose una importante influencia e interdependencia entre dichas formas y procesos, y el glaciarismo cuaternario y la morfodinámica periglaciar y nival actual.

Palabras clave: karst nival, glaciokarst, Macizo de las Ubiñas, Montañas Cantábricas 


\section{INTRODUCCIÓN}

La karstificación se produce, principalmente, debido a la disolución de los carbonatos presentes en las calizas y las dolomías (SWEETING, 1972; BÖGLI, 1980; WHITE, 1988; FORD y WILLIAMS, 2007), pudiendo darse en otro tipo de rocas como el yeso, la anhidrita o la halita. Sin embargo, la solubilidad de la calcita y la dolomita es muy escasa en agua pura. Por eso, es necesaria la intervención de una fuente de acidez, siendo la más importante para el desarrollo del karst el ácido carbónico, formado por la disolución de $\mathrm{CO}_{2}$ gaseoso (BÖGLI, 1980; WHITE, 1988; FORD y WILLIAMS, 2007). El ataque químico del ácido carbónico desencadena en la calcita la siguiente reacción reversible: $\mathrm{CaCO}_{3}+\mathrm{H}_{2} \mathrm{O}+\mathrm{CO}_{2} \leftrightarrow \mathrm{Ca}^{2+}+2 \mathrm{HCO}_{3}^{-}$. Por su parte, en la dolomita la reacción es: $\mathrm{CaMg}\left(\mathrm{CO}_{3}\right)_{2}+2 \mathrm{H}_{2} \mathrm{O}+2 \mathrm{CO}_{2} \leftrightarrow \mathrm{Ca}^{2+}+\mathrm{Mg}^{2+}+4 \mathrm{HCO}_{3}{ }^{-}$.

Como consecuencia, se produce la disolución del roquedo calcáreo o dolomítico, generándose morfologías que van desde unos pocos milímetros, como los microlapiaces, a centenares de metros, como en el caso de los poljés. Entre los factores que determinan el mayor o menor desarrollo del relieve kárstico, cabe citar la composición de la roca (su estructura y su porosidad), la topografía, la existencia o no de suelos y de vegetación, así como el clima (especialmente la temperatura, el régimen de precipitación, la presión del $\mathrm{CO}_{2}$ en el agua precipitada y de escorrentía, y el balance hídrico) (NICOD, 1972; BÖGLI, 1980; JENNINGS, 1985; WHITE, 1988; FORD y WILLIAMS, 2007). Para algunos autores el factor más importante es la cantidad de precipitación, hasta el punto de considerar que hay una relación lineal entre el grado de karstificación de un enclave y las precipitaciones que recibe (ej. LÓPEZ-MARTÍNEZ, 1984; WHITE, 1984 y 1988).

Los estudios sobre el karst constituyen una línea clave dentro de los estudios geomorfológicos, por su potencial desde el punto de vista paleoambiental y paleoclimático (DE WAELE et al., 2009). También debemos considerar su impronta paisajística y su valor patrimonial (ARTUGYAN, 2017), pues los paisajes kársticos ocupan el $\sim 20 \%$ de las tierras emergidas, y más de un cuarto de la población mundial vive en áreas kársticas o en sus proximidades (FORD y WILLIAMS, 2007; DE WAELE et al., 2009). Por tal motivo, abundan las investigaciones tanto a nivel internacional (ej. WOODWARD y LEWIN, 2009; VERESS, 2010; PARISE, 2011; SWEETING, 2012; ARTUGYAN, 2017; GÖKKAYA et al., 2021), como a escala de la Península Ibérica. En este ámbito, los trabajos de los últimos 50 años se han centrado en el estudio de tobas en su vertiente paleoambiental y geocronológica (ej. ORDÓÑEZ et al., 2005; GONZÁLEZ-AMUCHASTEGUI y SERRANO, 2007; CURRAS et al., 2012; GONZÁLEZ MARTÍN y GONZÁLEZ AMUCHASTEGUI, 2014) y también patrimonial (ej. FERNÁNDEZ et al., 2015), así como en aspectos morfológicos, morfométricos y cartográficos de ámbitos mediterráneos (LÓPEZ-LIMIA y LÓPEZBERMÚDEZ, 1985; GINÉS, 2001; FORNÓS et al., 2013), pirenaicos (LÓPEZMARTÍNEZ, 1984; JULIÁN, 1994; SALAZAR et al., 2016) y cantábricos, tanto costeros (ROMERO, 1984; ADRADOS, 2011; FLOR y FLOR-BLANCO, 2013) como 
de montaña. En este último caso, cabe mencionar las investigaciones efectuadas en diversas sierras calcáreas como el Sueve (SÁEZ HERNÁNDEZ y GÓMEZ DE BENITO, 1988), Peña Mea (ÁLVAREZ CAÑADA, 1997), y Sobia (RODRÍGUEZ PÉREZ, 1998, 2009, 2015), así como el Macizo de Valporquero (BAREA LUCHENA, 2001; REDONDO VEGA et al., 2002) y el valle del Curueño (GONZÁLEZGUTIÉRREZ et al., 2019), que siguen el último enfoque mencionado. Asimismo, también hay numerosas contribuciones sobre el karst de ámbitos de alta montaña como el Sinclinal de Saliencia y los Macizos de Somiedu (MUÑOZ JIMÉNEZ, 1980; RODRÍGUEZ PÉREZ, 2009, 2015), la Sierra de los Grajos (GONZÁLEZGUTIÉRREZ et al., 2017), el Macizo del Espigüete (PELLITERO, 2012) y, especialmente, los Picos de Europa, donde han sido realizados numerosos estudios sobre la tipología y la evolución de formas tanto exokársticas (MIOTKE, 1968; SANTOS ALONSO y MARQUÍNEZ GARCÍA, 2005; GONZÁLEZ-TRUEBA, 2006; RUIZ-FERNÁNDEZ， 2013; RUIZ-FERNÁNDEZ y SERRANO, 2010; RUIZFERNÁNDEZ et al., 2019) como endokársticas (SENIOR, 1987; RUIZ-FERNÁNDEZ y POBLETE, 2012; BALLESTEROS et al., 2011, 2015, 2019; GÓMEZ-LENDE, 2015; BALLESTEROS, 2016); incorporando en este último caso la perspectiva paleoambiental apoyada en aportaciones geocronológicas en parte de las contribuciones más recientes.

A pesar de las aportaciones citadas, distribuidas a lo largo de un amplio territorio, aún quedan importantes sectores de las Montañas Cantábricas sin estudiar específicamente. Este es el caso de las Ubiñas, que constituye uno de los macizos más elevados y con mayor desarrollo espacial del reborde montañoso del Noroeste de la Península Ibérica. En dicho macizo únicamente cabe citar los informes que acompañan algunas de las campañas espeleológicas que en él se han desarrollado. Por ello, en esta aportación, se propone estudiar el relieve kárstico del Macizo de las Ubiñas, con los objetivos específicos de:

i) Caracterizar las formas kársticas presentes, así como los procesos asociados.

ii) Estudiar sus interrelaciones con otros procesos y formas de modelado (principalmente con el glaciarismo pleistoceno y la morfodinámica periglaciar).

iii) Esclarecer las grandes fases en la evolución kárstica del macizo.

iv) Establecer una zonificación de los procesos y formas kársticas presentes a tenor del factor altitudinal.

\section{2. ÁREA DE ESTUDIO}

El Macizo de las Ubiñas se ubica en el sector central del Macizo Asturiano, siendo uno de los sistemas montañosos de mayor elevación de las Montañas Cantábricas. Destacan las cimas de El Fontán Sur (2.417 metros s.n.m.), El Fontán Norte (2.416 metros s.n.m.) y Penubina «La Grande»(2.414 metros s.n.m.). Geológicamente, dentro del sector 
Noroccidental del Macizo Hespérico, las Ubiñas se ubican en el área centro-Sudoeste de la Zona Cantábrica (LOTZE, 1945), la cual se encuentra rodeada por todo su flanco occidental y meridional por la Zona Asturoccidental-Leonesa (JULIVERT, 1983; RODRÍGUEZ FERNÁNDEZ, 1983). Específicamente, las Ubiñas se encuadran dentro de un sector de contacto entre la Región de Pliegues y Mantos, situada al Oeste e integrada por el Manto de Bodón en la Unidad de la Sobia-Bodón, y la Cuenca Carbonífera Central, hacia el Este (figura 1).

Asimismo, el área de estudio se asienta sobre la bisectriz del ángulo que forma el Arco Astúrico, conocido también como Rodilla Astúrica y Arco Ibero-Armoricano (CASTAÑ́́N, 1983; ALLER, 1984) en un sector atravesado por la Falla de León, que separa la Región de Pliegues y Mantos (de vergencia centrípeta respecto al trazado del Arco Astúrico), y la Cuenca Carbonífera Central (de vergencia centrífuga), por lo que ambas unidades geológicas se disponen con vergencias opuestas (LLOPIS LLADÓ, 1964).

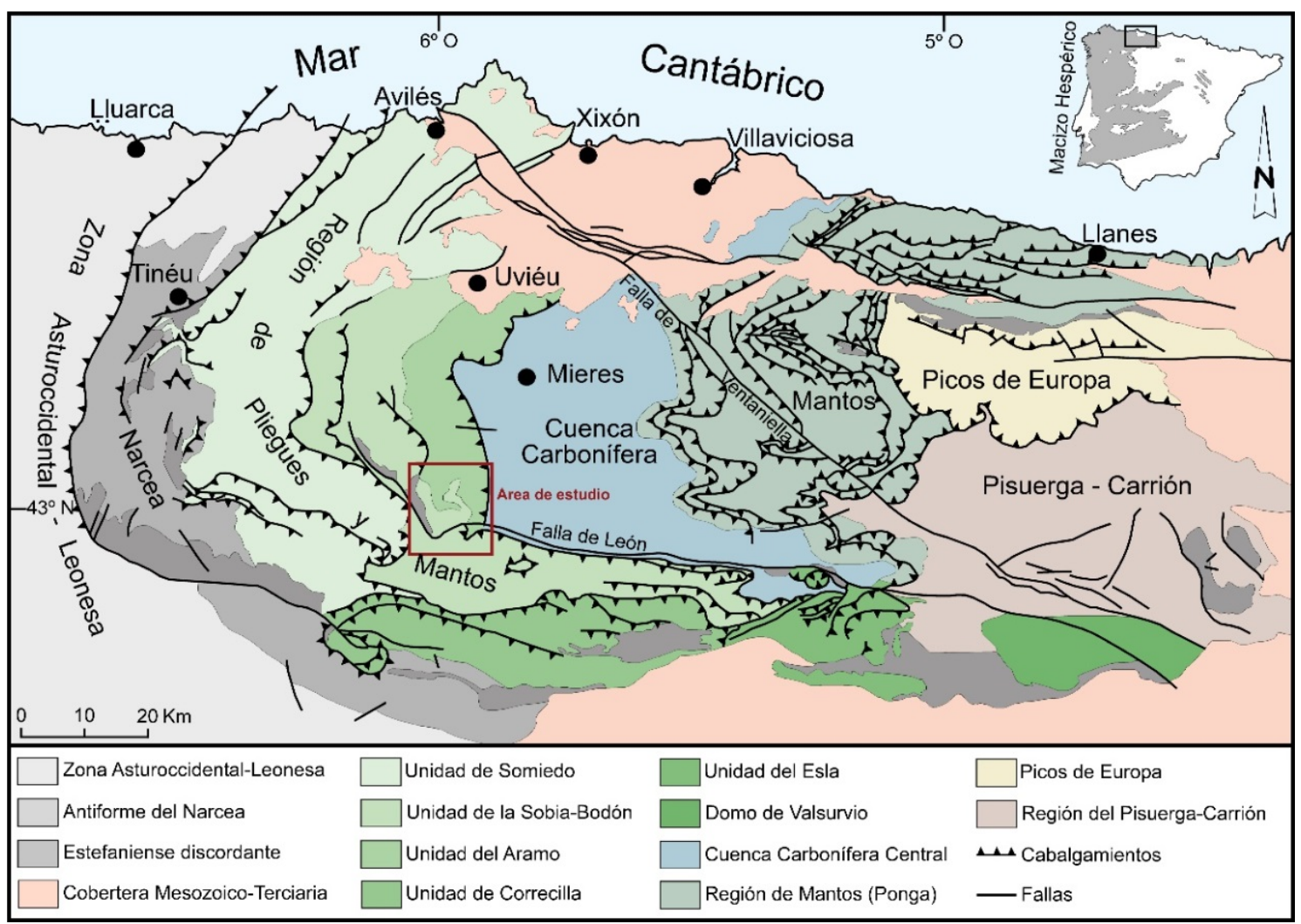

Figura 1. Unidades estructurales de la Zona Cantábrica, con la localización del área de estudio (rectángulo rojo). Fuente: elaboración propia a partir de JULIVERT (1983) y RODRÍGUEZ FERNÁNDEZ (1983).

Con respecto a la litoestratigrafía, este macizo está constituido por un potente armazón calcáreo que conforma sus cresterías y zonas más elevadas. Por su parte, en su periferia y en algunos valles y crestas montañosas secundarias afloran dolomías, pizarras, cuarcitas y areniscas (figura 2). No obstante, también hay presencia de otros materiales como conglomerados, rocas volcánicas y lutitas. Casi la totalidad del 
roquedo del área de estudio es de edad Paleozoica (entre el Cámbrico y el Carbonífero), aunque existe, de forma testimonial, roquedo del Mesozoico (Cretácico) en el sector meridional. Dichos materiales, que están afectados por dos orogenias (la Hercínica, de la cual derivan sus rasgos tectónicos principales, y la Alpina, que rejuveneció dicho ámbito), fueron plegados, fracturados y sobreelevados hasta dar lugar a su actual disposición morfoestructural. Por tanto, están organizados en estructuras de naturaleza diferenciada, primando diversos tipos de pliegues y escamas cabalgantes, que generan importantes desniveles y escarpes calcáreos de paredes subverticales, afectados en detalle por debilidades estructurales asociadas a fracturas. Cabe señalar, asimismo, el importante papel de la Falla de León en su configuración (TRUYOLS et al., 1982).

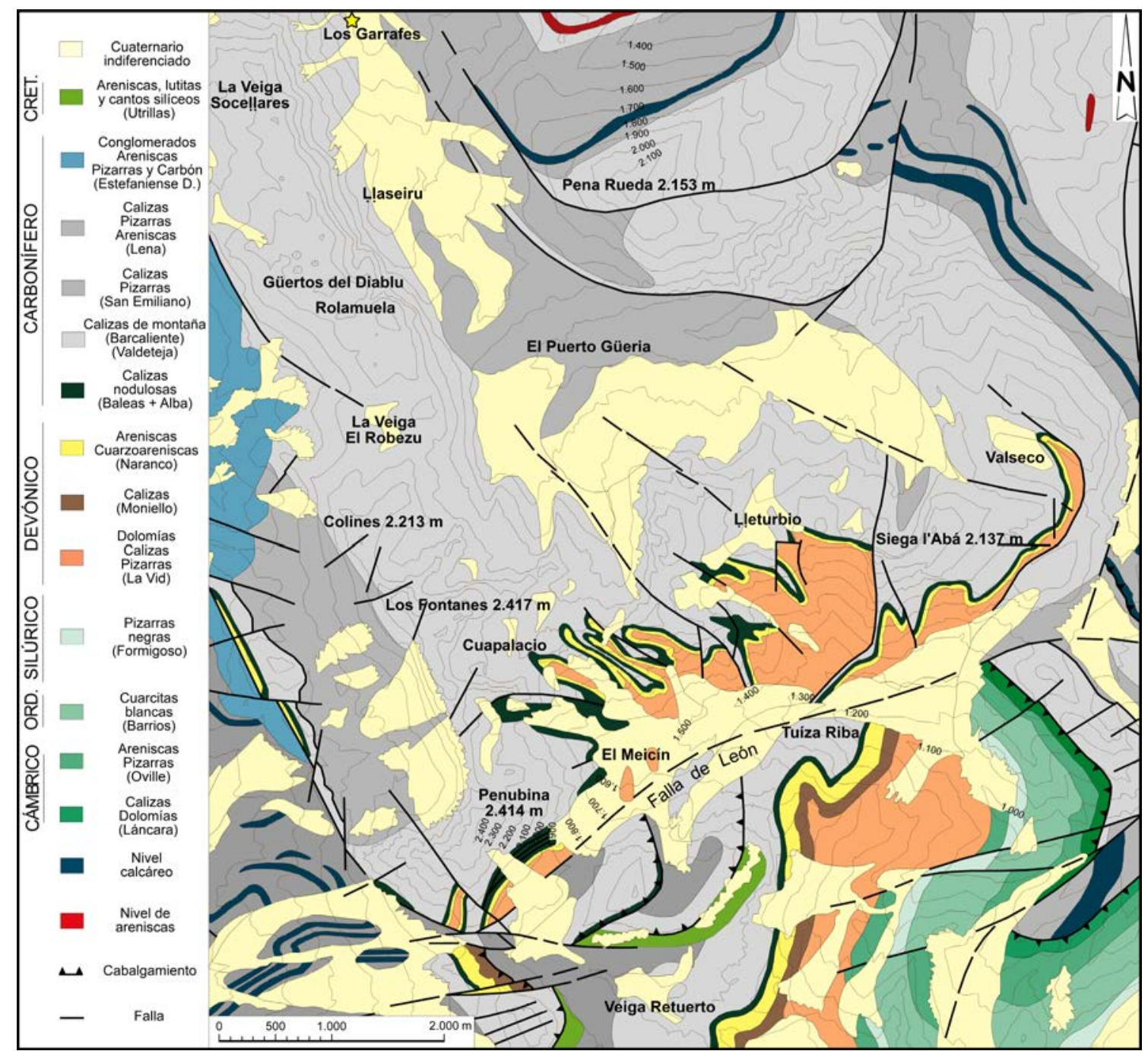

Figura 2. Mapa Geológico del Macizo de las Ubiñas. Fuente: elaboración propia a partir de: MARCOS et al. (1980), ALLER (1984), MARTÍNEZ ABAD (2007) y ALONSO et al. (2008).

En consecuencia, gran parte de los cordales culminantes y las principales cumbres de las Ubiñas están labradas en calizas, con potencias superiores a los 1.000 metros en la vertical, que puntualmente llegan a alcazar los 1.500 metros. Esto es posible gracias a la 
continuidad estratigráfica de calizas de diferentes formaciones en unas partes y otras de las Ubiñas, como: Valdeteja (que localmente supera los 500 metros de espesor), Barcaliente (que alcanza más de 1.000 metros de potencia al Norte del macizo, si bien en otras partes sus espesores son menores), Alba y Baleas (alrededor de 50 metros de grosor), Moniello (aproximadamente 200 metros de espesor), así como las dolomías de los niveles inferiores del Grupo La Vid (de hasta 500 metros de potencia) (TRUYOLS et al., 1982; MARTÍNEZ ABAD, 2007). Estos espesores y las fracturas, diaclasas y fallas que los cincelan, así como la abundancia de precipitaciones, muchas de ellas en forma de nieve, han esculpido un relieve kárstico de gran complejidad y entidad dentro de las Montañas Cantábricas.

En cuanto al clima de las Ubiñas, a partir de las estaciones meteorológicas próximas de la Agencia Estatal de Meteorología (AEMET) se han establecido unas precipitaciones medias de entre 958 y $1.406 \mathrm{~mm} / \mathrm{año}$, existiendo una marcada sombra pluviométrica entre la parte Norte y Sur de la divisoria hidrográfica a que da lugar el macizo. En los sectores de mayor altitud buena parte de esas percipitaciones son en forma de nieve, al igual que acontece en otros conjuntos montañosos situados al Este y al Oeste de las Ubiñas, como son los Picos de Europa y Lleitariegos, en los cuales se han documentado 85 y 83 días de nevada al año, respectivamente. Según MUÑóZ-JIMÉNEZ (1982), en el primer caso dichos días de nieve concentrarían el 70\% del total de precipitaciones anuales. Consecuentemente, las copiosas precipitaciones nivales que se dan en los sectores de mayor altitud del Macizo de las Ubiñas, generan abundantes aguas de fusión que contribuyen decisivamente al desarrollo del karst y alimentan torrentes y acuíferos durante todo o prácticamente todo el año. Este aporte de aguas de fusión es especialmente durante la primavera y los inicios del verano.

Por otro lado, en las estaciones circundantes las temperaturas medias anuales oscilan entre $6,3{ }^{\circ} \mathrm{C}$ y $7,2{ }^{\circ} \mathrm{C}$, alcanzando amplitudes térmicas medias de $12,5{ }^{\circ} \mathrm{C}$ a $13{ }^{\circ} \mathrm{C}$. Sin embargo, estos valores son mucho más bajos en las partes altas. Así, a partir del gradiente adiabático vertical de $0,56{ }^{\circ} \mathrm{C}$ calculado por MUÑOZ-JIMÉNEZ (1982) para el conjunto de Asturias, la isoterma de $0{ }^{\circ} \mathrm{C}$ se eleva a 2.400-2.500 metros s.n.m., mientras que la de $2,7^{\circ} \mathrm{C}$ estaría emplazada a 2.000 metros s.n.m. Este mismo autor señala que las Ubiñas se encuadran dentro del tipo Dfsc según la clasificación de Köppen.

Desde el punto de vista biogeográfico, las Ubiñas están dominadas por los bosques de hayas (Fagus sylvatica) y localmente por robles albares (Quercus petraea) en el piso montaño, además de por bosques clareados mixtos de acebos (Ilex aquifolium), tejos (Taxus baccata) y servales (Sorbus aucuparia), como acontece en El Puerto Güeria. Sin embargo, las formaciones que más espacio ocupan en las Ubiñas son las arbustivas y herbáceas, fruto de las condiciones bioclimáticas típicas del piso subalpino y alpino, pero también de la actividad humana, ganado espacios pastables en los pisos inferiores. Y es que históricamente, las principales actividades humanas en este ámbito has sido las agro-silvo-pastoriles de corte tradicional (especialmente la ganardería, y dentro de ella la trashumancia), que actualmente están en franco retroceso a la par que gana protagonismo el turismo de montaña, favorecido por la declaración de las Ubiñas como 
parte de dos Parques Naturales: P. N. de Las Ubiñas y La Mesa, (Asturias, 2006), y P. N de Babia y Luna (León, 2015), y de las Reservas de la Biosfera homónimas (la parte leonesa fue declarada en 2004, y el sector asturiano en 2012).

\section{METODOLOGÍA}

Este trabajo se basa en un reconocimiento sistemático del Macizo de las Ubiñas, a partir del trabajo de campo desarrollado entre los años 2012 y 2021. A lo largo de los transectos efectuados, se ha estudiado la distribución espacial de las formas y procesos kársticos existentes, su gradación altitudinal, así como sus interferencias con otras formas de relieve (específicamente con las formas derivadas del glaciarismo cuaternario conservadas en el macizo, así como con las de origen periglaciar y nival). Dicha información se ha sistematizado en un mapa geomorfológico de todo el macizo realizado a escala original 1:10.000, del que han sido incluidos en este estudio dos sectores representativos del modelado kárstico existente. El método utilizado en la confección de la cartografía geomorfológica es el RCP 77 del Centre National de la Recherche Scientifique (CNRS; JOLY, 1997) si bien se han incorporado adaptaciones propias (RUIZ-FERNÁNDEZ, 2011). El programa utilizado para la salida final de la cartografía ha sido CorelDraw en su versión Graphics Suite 2021. La terminología empleada, primordialmente en el caso de los principales tipos de lapiaz, es la comúnmente utilizada en los manuales de referencia (NICOD, 1972; SWEETING, 1972; JENNINGS, 1985; WHITE, 1988; FORD y WILLIAMS, 2007; VERESS, 2010). El apartado referido al endokarst se ha elaborado a partir de los datos aportados en diferentes memorias espeleológicas que reflejan las campañas llevadas a cabo en las Ubiñas (SUÁREZ URIARTE, 1922; RODRÍGUEZ PEVIDA et al., 1982; PUERTA ELORZA, 2000; BALLESTEROS, 2008; GRUPO ESPELEOLÓGICO POLIFEMO, 2010; INTERCLUB UBIÑA DEL COLECTIVU ASTURIANU D’ESPELEÓLOGOS, 2013), así como a partir de la obra de síntesis de Puch (1998) y de los datos suministrados por la Federación d'Espeleoloxía del Principáu d'Asturies (FESPA).

\section{RESULTADOS}

Las Ubiñas cuentan con una red fluvial centrífuga (ríos Güerna, Llindes, Ricao y Urugu) que nace en los sectores intermedios y bajos del macizo, a favor del contacto entre los materiales carbonatados y los impermeables (especialmente las pizarras). Por tanto, las partes medias y altas, de naturaleza caliza, se definen por la disolución superficial de dichas rocas y la percolación de las escorrentías hacia el interior del armazón calcáreo, desarrollando el endokarst, imposibilitando que fluyan corrientes superficiales y generando, por tanto, un holokarst (CVIJIĆ, 1893). 


\subsection{Las formas exokársticas}

Debido a la continua y prolongada exposición a unas condiciones ambientales que contribuyen la erosión de las superficies calizas, en las Ubiñas se han generado numerosas formas de origen exokárstico y endokárstico que serán tratadas en los siguientes apartados.

\subsubsection{Macroformas exokársticas: cubetas glaciokársticas}

Las cubetas glaciokársticas constituyen la única forma exokárstica mayor presente en el Macizo de las Ubiñas, ya que no existen aquí otras formas tales como poljés. Estas geoformas se caracterizan por ser depresiones bien definidas y de gran tamaño, generalmente hectométrico o kilométrico, cuya génesis es kárstica, primeramente, si bien posteriormente han sido retrabajadas por los glaciares a favor de la topografía previa y de los condicionantes estructurales. Frecuentemente se distribuyen de forma escalonada en las partes superiores de los valles, quedando separadas entre sí por umbrales rocosos.

Tabla 1. Cubetas glaciokársticas del Macizo de las Ubiñas. «Sup» (superficie en hectáreas), «Lo +» (longitud máxima en metros), «An +» (anchura máxima en metros), «Al +» (altitud máxima en metros s.n.m), «Al -» (altitud mínima en metros s.n.m)

\begin{tabular}{|c|c|c|c|c|c|c|}
\hline $\begin{array}{c}\text { Nombre } \\
\text { Cubeta glaciokárstica }\end{array}$ & $\begin{array}{c}\text { Sup } \\
(\mathbf{h a})\end{array}$ & $\begin{array}{c}\text { Lo }+ \\
(\mathbf{m})\end{array}$ & $\begin{array}{c}\text { An }+ \\
(\mathbf{m})\end{array}$ & $\begin{array}{c}\text { Al }+ \\
(\mathbf{m s n m})\end{array}$ & $\begin{array}{c}\text { Morfología } \\
(\mathbf{m s n m})\end{array}$ & \\
\hline Veiga Candiolles & 68,9 & 1.600 & 600 & 1.701 & 1.686 & Irreg-Oval \\
\hline Veiga Retuerto & 74,8 & 1.450 & 850 & 1.818 & 1.778 & Irreg-Oval \\
\hline Fuexos de Cuapalacio 1 & 2 & 170 & 160 & 2.100 & 2.090 & Trian-Oval \\
\hline Fuexos de Cuapalacio 2 & 7,8 & 550 & 270 & 1.950 & 1.934 & Ovalada \\
\hline Fuexu Llluengu 1 & 4,2 & 330 & 290 & 1.987 & 1.976 & Triangular \\
\hline Fuexu Lḷuengu 2 & 8,1 & 390 & 450 & 1.851 & 1.830 & Irregular \\
\hline Fuexos de Colines & 12,4 & 630 & 280 & 2.000 & 1.941 & Ovalada \\
\hline Mayéu'l Lḷegu (Meicín) & 6,5 & 400 & 270 & 1.550 & 1.544 & Ovalada \\
\hline Veiga'l Robezu & 24,3 & 530 & 770 & 1.912 & 1.906 & Irregular \\
\hline Veiga Socellares & 47,4 & 1.140 & 700 & 1.779 & 1.739 & Ovalada \\
\hline Fuexos del Siega l'Abá & 7 & 300 & 250 & 1.745 & 1.734 & Circular \\
\hline Valseco & 28,9 & 800 & 450 & 1.667 & 1.651 & Ovalada \\
\hline Lḷaseiru & 12,4 & 450 & 320 & 1.374 & 1.368 & Ovalada \\
\hline
\end{tabular}

El tamaño de estas depresiones oscila entre 2 hectáreas en Cuapalacio y 74,8 hectáreas en la Veiga Retuerto, siendo habitualmente ovaladas, por lo que tienden a ser 
sensiblemente más largas que anchas, aunque también existen formas irregulares (tabla 1). Las cubetas glaciokársticas se encuentran generalmente por encima de 1.700 metros s.n.m., (únicamente tres se formaron por debajo de dicha cota: Llaseiru, El Mayéu'l Llegu y Valseco). Asimismo, las de mayores dimensiones son las que se encuentran en altitudes medias, destacando la Veiga Retuerto, como la más extensa, y otras como la Veiga Candiolles (68,9 hectáreas), mientras que las de mayor altitud tienden a ser las de menor tamaño. Además, como las cubetas glaciokársticas suelen situarse en la horquilla entre 1.700 y 2.100 metros s.n.m., coinciden con algunas cabeceras de valles glaciares.

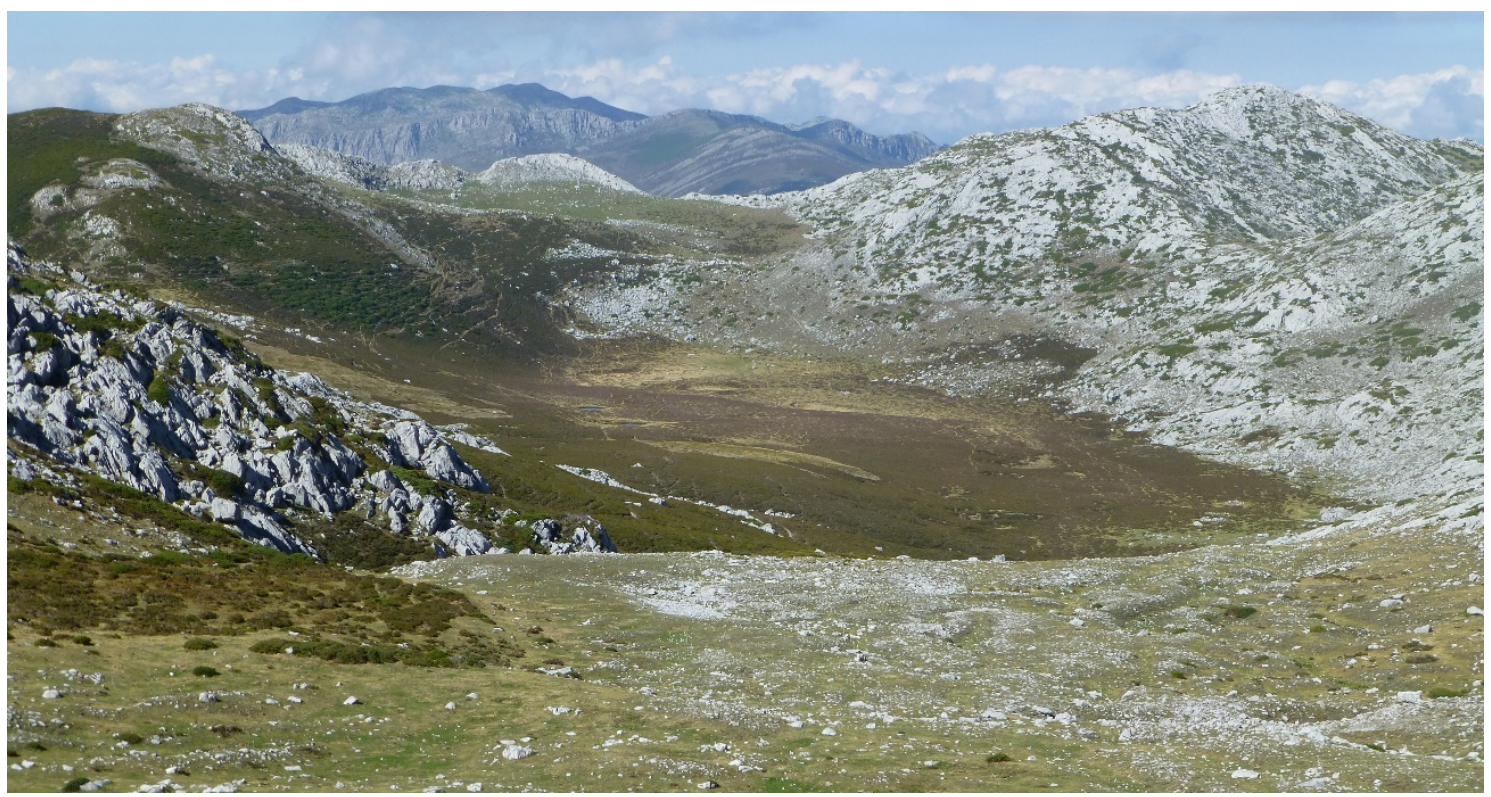

Figura 3. Cubeta de glaciokárstica de La Veiga Socelḷares. Fuente: realización propia.

En cuanto al desnivel de estas depresiones, entendiéndose como tal la diferencia de altitud entre el punto más deprimido de la cubeta glaciokárstica y la altitud mínima de su perímetro, oscila generalmente entre 10 y 50 metros. No obstante, a este respecto hay que aclarar que las cubetas de las Ubiñas suelen tener un sector distal conforme a la inclinación del valle en el que se inscriben, cuyo umbral se encuentra sensiblemente por debajo del resto de paredes que rodean a estas depresiones (figura 3). Es decir, suelen tener una disposición abierta valle abajo.

En el interior de las cubetas glaciokársticas estudiadas es habitual encontrar numerosas depresiones que suelen oscilar entre 5 y 10 metros de diámetro, evidenciando que han sufrido un retoque kárstico postglaciar. Así pues, las dolinas nivales, los fuexos, las simas y los pozos nivokársticos, que proliferan en los puntos estructuralmente más débiles, así como sumideros y surgencias, tienden a horadar la superficie de estos espacios, generando un terreno rugoso y caótico. Estas morfologías superficiales captan el agua hacia el interior del armazón rocoso, como en la Veiga Retuerto, la Veiga Socellares (figuras 3 y 4) y la Veiga Candiolles (figuras 5 y 6). 


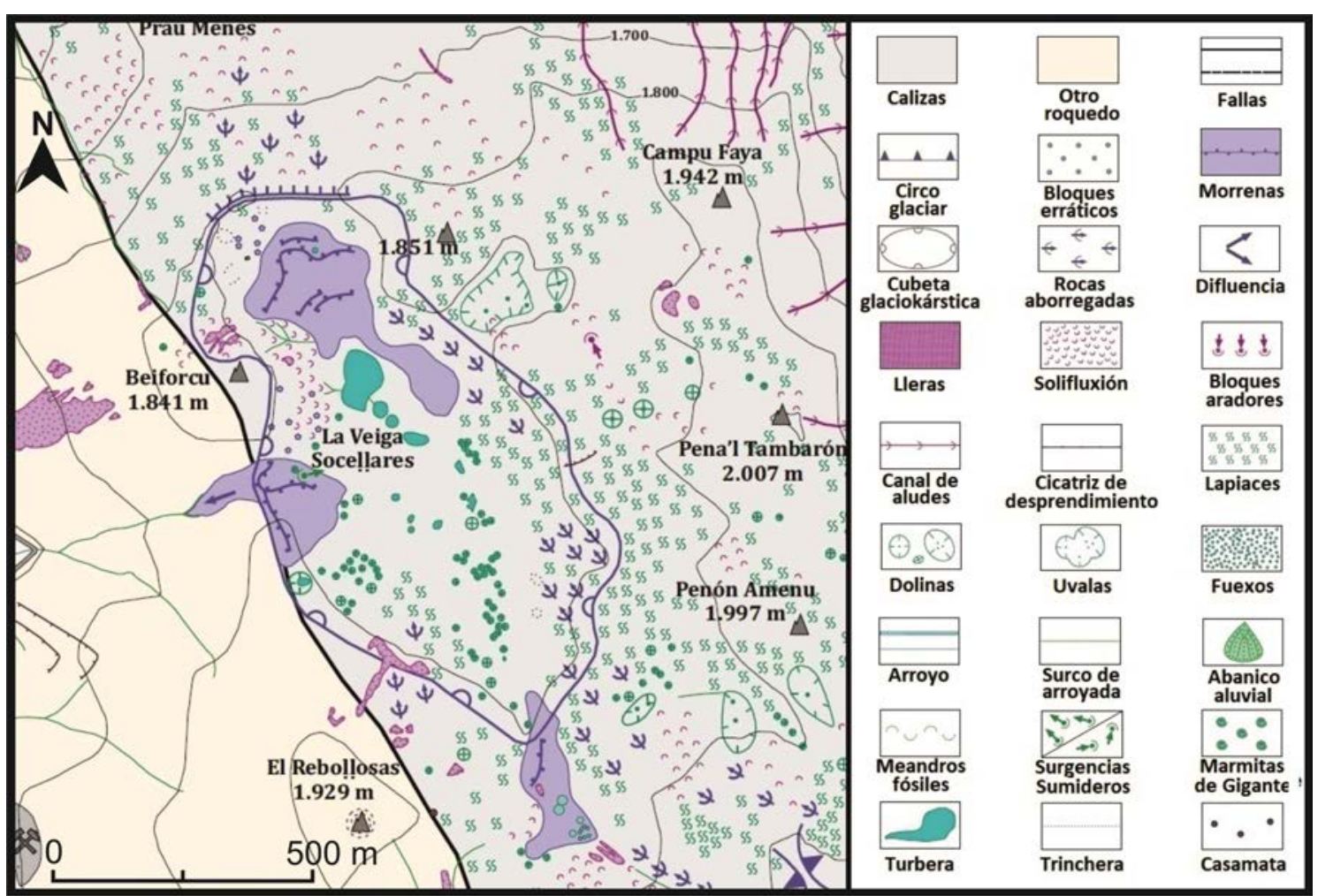

Figura 4. Mapa geomorfológico del entorno de La Veiga Socellares. Fuente: realización propia.

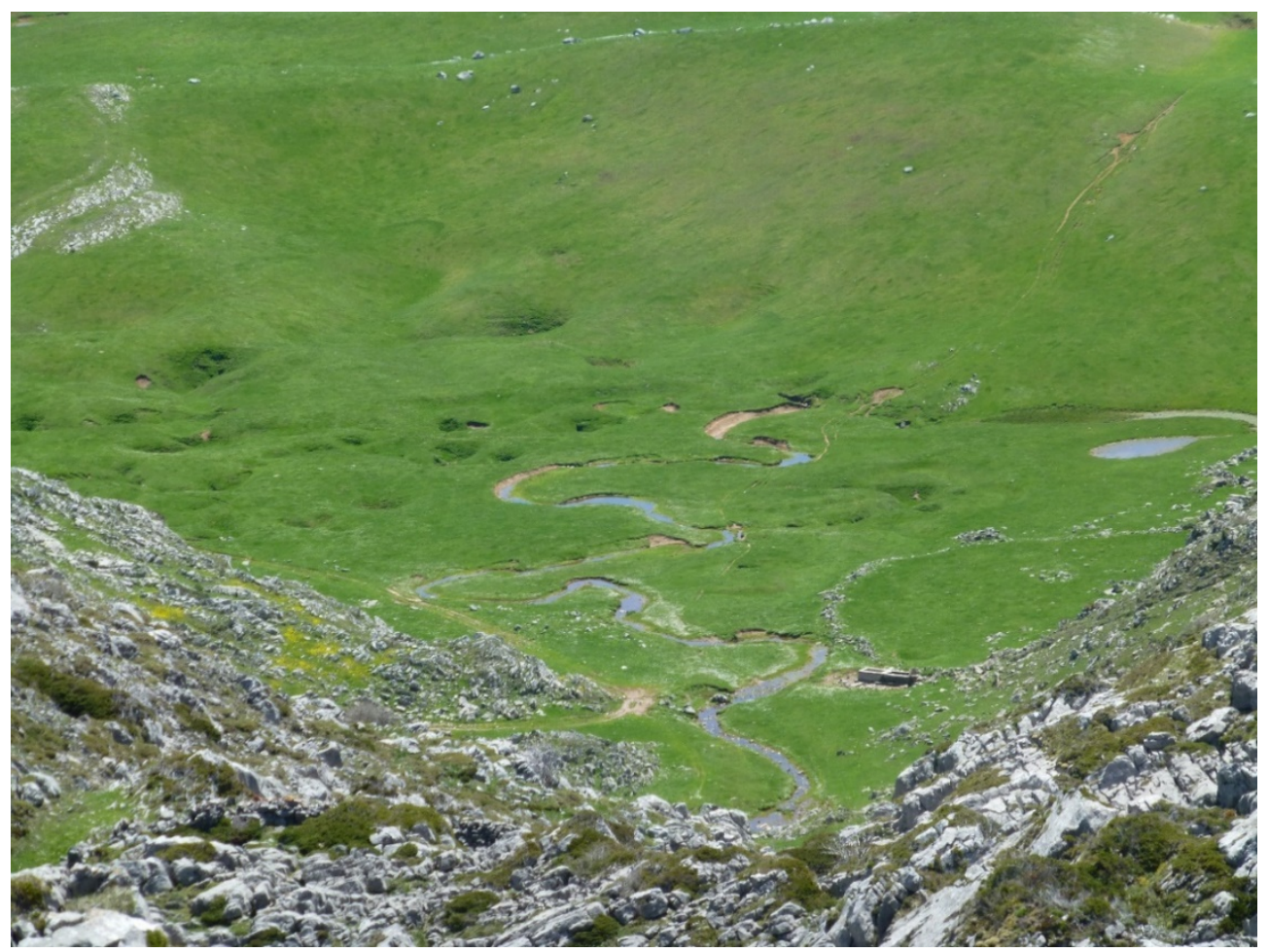

Figura 5. Los Ollones (Veiga Candiolles). Numerosas dolinas de recubrimineto (fuexos) de tamaño métrico retocan el suelo de esta cubeta glaciokárstica. Se observa cómo el curso de agua es canalizado hacia un sumidero, donde se infiltra. El abrevadero de la parte inferior sirve de escala. Fuente: realización propia. 


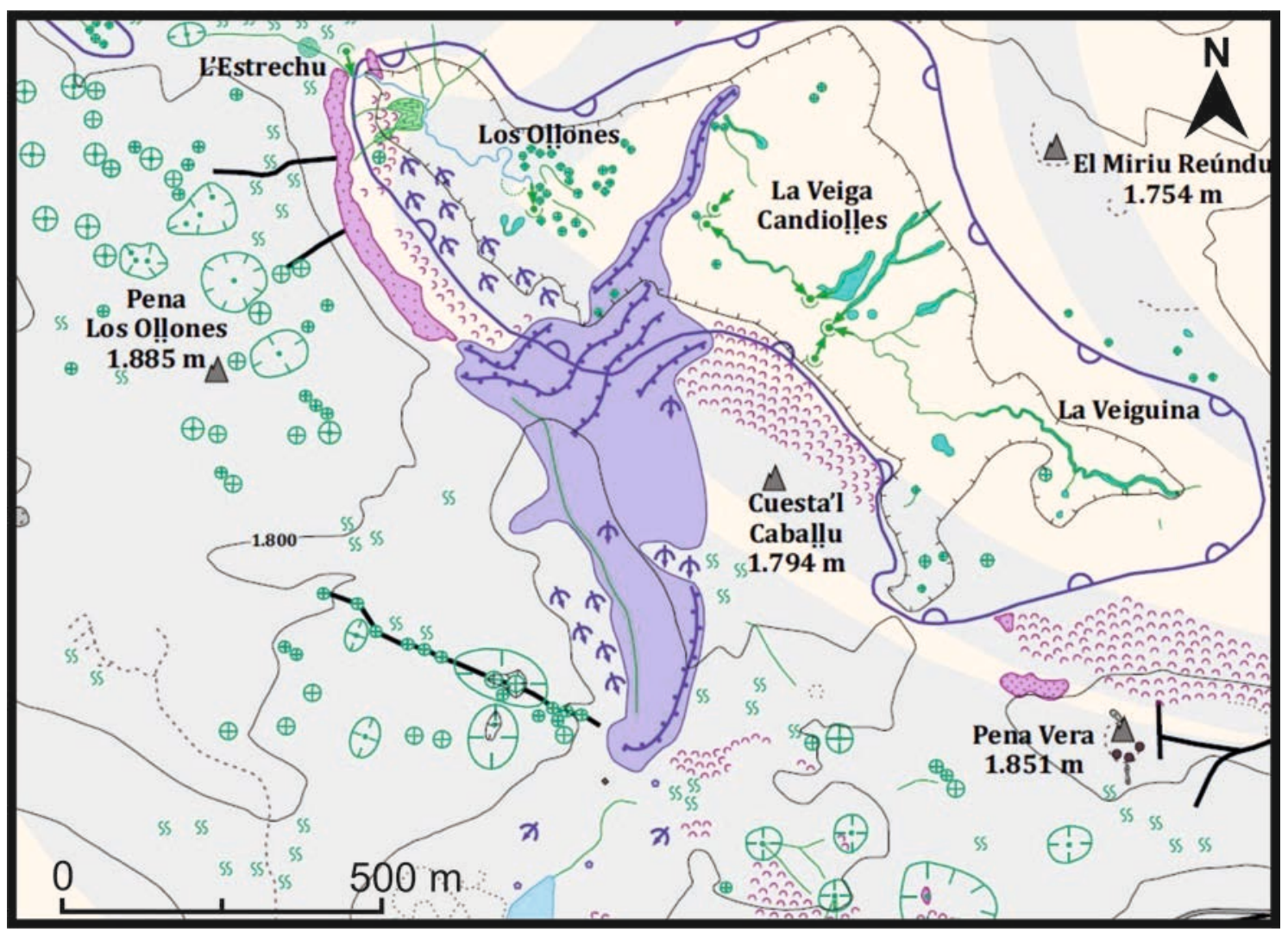

Figura 6. Mapa geomorfológico del entorno de La Veiga Candiolles. Leyenda compartida con la figura 4. Fuente: realización propia.

Tras la deglaciación finipleistocena, y a lo largo de todo el Holoceno, las cubetas glaciokársticas han experimentado rellenos sedimentarios de diversa génesis. Las cubetas situadas a menor altitud contienen habitualmente numerosos cordones y arcos morrénicos y su superficie frecuentemente está tapizada por till. No obstante, debido a su morfología cóncava, también reciben abundantes aportes de arcillas de descalcificación transportadas por los pequeños cursos de agua, lo que puntualmente ha impermeabilizado algunas partes, permitiendo que el agua fluya por ellas intermitentemente (figura 5). Incluso, en el caso de Lḷaseiru, se ha desarrollado una turbera de 7,1 hectáreas que se transforma en un lago durante el deshielo, debido a que el sumidero de la depresión kárstica no es capaz de drenar todas las escorrentías que le llegan en los episodios de mayores aportes hídricos. En cambio, las cubetas emplazadas a mayores altitudes, suelen tener sus fondos tapizados por derrubios de carácter mixto, tanto glaciares como periglaciares, generando superficies caóticas donde se pueden encontrar bloques erráticos, till, derrubios de ladera y las ya mencionadas depresiones de tamaño medio y menor, como en los Fuexos de Colines, los Fuexos de Cuapalacio y El Fuexu Lḷuengu (figura 7).

En definitiva, la actividad y evolución de estas depresiones continúa desde la retirada de los glaciares con la infiltración de agua de escorrentía y de fusión nival de forma difusa, mediante su percolación a través de sumideros bien desarrollados, pero también de las múltiples oquedades generadas a favor de la red de discontinuidades estructurales propia de las calizas carboníferas. Externamente, los afloramientos rocosos 
que integran a las depresiones glaciokársticas están retocados por lapiaces de diferentes tamaños y formas, siendo especialmente abundantes y bien desarrollados los lapiaces libres de influencia nival. Asimismo, también están afectadas por otros procesos y formas de modelado como la crioclastia.

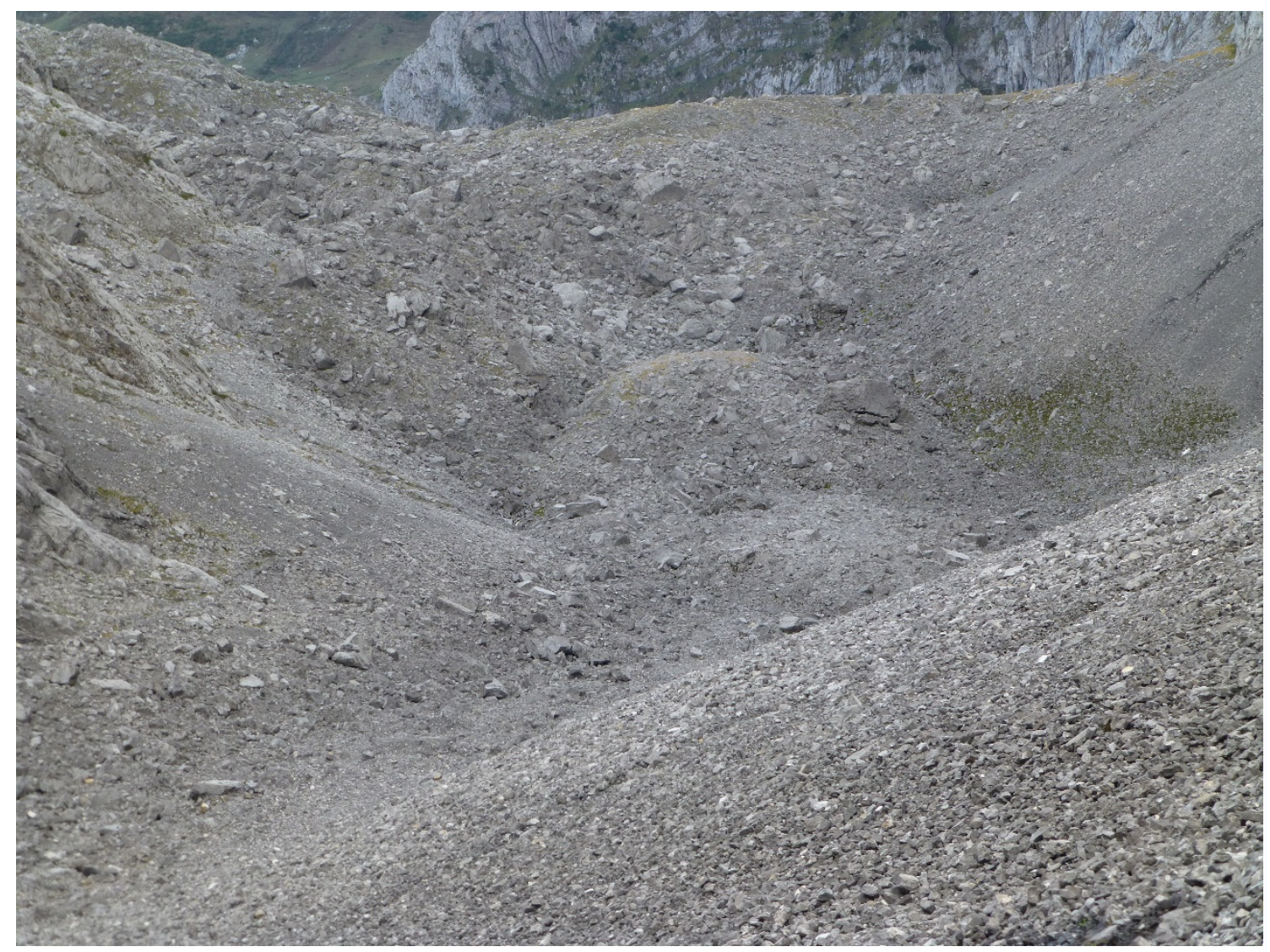

Figura 7. El Fuexu Lḷuengu (1). Cubeta glaciokárstica totalmente tapizada por derrubios de ladera en sus laterales y por morrenas al frente y en su parte central. Fuente: realización propia.

\subsubsection{Mesoformas exokársticas}

El Macizo de las Ubiñas cuenta con diversas morfologías exokársticas de escala media, como dolinas, uvalas, fuexos o dolinas de recubrimiento, pozos nivokársticos y bogaces (tabla 2).

4.1.2.1. Dolinas. Las dolinas o toll los son depresiones kársticas de orden métrico a hectométrico con forma de cono o embudo, vertientes de más o menos inclinación, y cuya planta presenta un contorno circular o elíptico. Proliferan a favor de las debilidades estructurales del armazón calcáreo. Sus formas se deben al ensanchamiento de las discontinuidades generadas por fallas, fracturas y redes de diaclasas, a partir de la disolución de los carbonatos y/o el hundimiento superficial de la masa calcárea debido al colapso de una cámara o galería en el subsuelo. Estas depresiones dirigen la 
percolación hídrica hacia las galerías y conductos endokársticos del interior del roquedo. Son propias de los sectores de media y alta montaña de las Ubiñas.

Las dimensiones observadas varían desde diámetros inferiores a 5 metros, hasta la existente en L'Estrechu, cuyo eje mayor alcanza 340 metros. Sus profundidades oscilan entre 1 y 30 metros, como las catalogadas en el margen al Este de la Veiga Socellares (figura 4), la Veiga los Pozos, El Fuexu Ḷluengu, El Planón, la vertiente septentrional del Siega l'Abá, L'Estrechu y los Pozos de la Nieve en la Pena los Oḷones (figura 6). Ocasionalmente su profundidad supera el tamaño de su eje mayor, y por tanto su morfología es más vertical, principalmente en forma de embudo o cono. Las dolinas de mayor tamaño suelen albergar en su interior otras de menor tamaño, principalmente fuexos, tal y como se aprecia en la figura 8.

En las Ubiñas las dolinas suelen tener su fondo tapizado por derrubios y/o arcillas de descalcificación, especialmente aquellas de mayor extensión. A su vez, en los sectores de suelos más evolucionados, como en la Veiga Candiolles (figura 5), las dolinas están intensamente vegetadas. Los afloramientos de roca in situ se circunscriben principalmente a las paredes de las dolinas (figura 8).

4.1.2.2. Uvalas. Se trata de depresiones de planta polilobulada y generalmente mayor extensión que las dolinas (0,5-2,8 hectáreas). En las Ubiñas suelen estar integradas por agrupaciones de dos a cuatro dolinas de medio o gran tamaño (85-250 metros de eje mayor). Dentro del macizo se distribuyen por las plataformas calcáreas de mayor desarrollo, como los Güertos del Diablu y la Pena los Ollones. Al igual que en el caso de las cubetas glaciokársticas y las dolinas individualizadas, las uvalas están tapizadas por derrubios y arcillas de descalcificación.

4.1.2.3. Fuexos. Los fuexos son dolinas de recubrimiento, es decir, depresiones kársticas de mediano y pequeño tamaño (diámetros de uno a seis metros) totalmente tapizadas por formaciones superficiales de derrubios, de planta circular u ovalada y cuya profundidad nunca es mayor que el diámetro de su contorno. En los Picos de Europa se los conoce con el término de «boches», el cual ha sido utilizado por CASTAÑón y FROCHOSO (1994, 1998), GONZÁLEZ-TRUEBA (2006), PELLITERO (2012), este último en el Macizo del Espigüete, RUIZ-FERNÁNDEZ (2013) y RUIZ-FERNÁNDEZ et al. (2019). La evolución de los fuexos (figura 9) se debe al colapso y/o la disolución de las calizas infrayacentes con respecto a los recubrimientos sedimentarios ya citados. En las Ubiñas proliferan en las cubetas glaciokársticas, como la Veiga Socelllares y la Veiga'l Robezu, y en las partes superiores de los valles glaciares, como El Planón, Cuapalacio, El Fuexu Lluengu, Colines, Siega l'Abá y Cerreo, cuyo fondo está tapizado por depósitos glaciares y/o derrubios de ladera. También aparecen asociados a recubrimientos de origen torrencial y lacustre, y frecuentemente conforman campos de fuexos con decenas de estas morfologías. 
Tabla 2. Esquema resumen de las formas kársticas del Macizo de las Ubiñas

\begin{tabular}{|c|c|c|c|c|}
\hline \multirow[b]{2}{*}{$\frac{0}{0}$} & \multirow{2}{*}{ 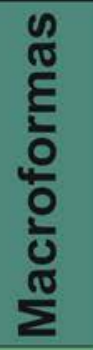 } & \multirow[b]{2}{*}{$\begin{array}{c}\text { Cubetas } \\
\text { glaciokársticas }\end{array}$} & Características & Emplazamiento \\
\hline & & & $\begin{array}{l}\text { Depresiones kársticas } \\
\text { de mayor tamaño del } \\
\text { Macizo de las Ubiñas. } \\
\text { Formas generalmente } \\
\text { más largas que anchas. } \\
\text { Entre } 2 \text { y } 74,8 \text { hectáreas. }\end{array}$ & $\begin{array}{c}\text { Parte superior de } \\
\text { plataformas calcáreas } \\
\text { (ej. Güertos del Diablu). } \\
\text { Circos y valles glaciares } \\
\text { (ej. Cuapalacio, Colines } \\
\text { La Veiga Candiolles, etc.) }\end{array}$ \\
\hline & \multirow{5}{*}{ 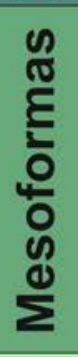 } & Dolinas (To!los) & $\begin{array}{c}\text { Depresiones métricas a } \\
\text { decamétricas en forma } \\
\text { de cono o cilindro. }\end{array}$ & \multirow{2}{*}{$\begin{array}{l}\text { En plataformas calcáreas } \\
\text { con pendientes suaves y } \\
\text { en lechos de circos y } \\
\text { valles glaciares. }\end{array}$} \\
\hline \multirow{3}{*}{ ๘ } & & Uvalas & Polilobuladas. 2-4 dolinas. & \\
\hline & & Fuexos & \multirow{3}{*}{\begin{tabular}{|c|} 
Dolinas de recubrimiento \\
Diámetros de $1-6$ metros. \\
Albergan neveros. Más \\
profundos que anchos. \\
De longitudes métricas \\
a decamétricas.
\end{tabular}} & $\begin{array}{l}\text { En valles glaciares con } \\
\text { abundancia de till. }\end{array}$ \\
\hline & & Pozos nivokársticos & & \multirow{2}{*}{$\begin{array}{c}\text { En umbrales rocosos y } \\
\text { sectores con roca al } \\
\text { descubierto. }\end{array}$} \\
\hline & & Bogaces & & \\
\hline \multirow{4}{*}{ E } & \multirow{4}{*}{ 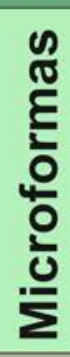 } & $\begin{array}{l}\text { Lapiaces estructur } \\
\text { Splitkarren - Kluftkarren - }\end{array}$ & \multirow{3}{*}{$\begin{array}{c}\text { Discontinuidades } \\
\text { milimétricas a métricas. } \\
\text { Acanaladuras y surcos } \\
\text { rectilíneos separados por } \\
\text { crestas. Mäanderkarren } \\
\text { tiene forma meandriforme } \\
\text { Formas laminares. }\end{array}$} & $\begin{array}{c}\text { Frecuentes en las } \\
\text { superficies calcáreas. }\end{array}$ \\
\hline & & $\begin{array}{l}\text { Lapiaces libres } \\
\text { Rillenkarren - Rinnenkarren } \\
\text { Wandkarren - Mäanderkarren }\end{array}$ & & $\begin{array}{c}\text { En paredes calizas con } \\
\text { pendientes entre }>60^{\circ}-20^{\circ} \\
\text { Mäanderkarren }<20^{\circ} \text {. }\end{array}$ \\
\hline & & Solution ripples - Trittkarren & & Superficies allanadas. \\
\hline & & $\begin{array}{l}\text { Lapiaces cubiertos } \\
\text { Kamenitzas } \\
\text { Hohlkarren - Rundkarren }\end{array}$ & \begin{tabular}{|c|} 
Cubetas centimétricas. \\
Surcos y estructuras \\
tubulares redondeadas.
\end{tabular} & $\begin{array}{l}\text { Bajo cubiertas edáficas, } \\
\text { en zonas exhumadas o } \\
\text { en umbrales calcáreos. }\end{array}$ \\
\hline \multirow{3}{*}{\multicolumn{2}{|c|}{ 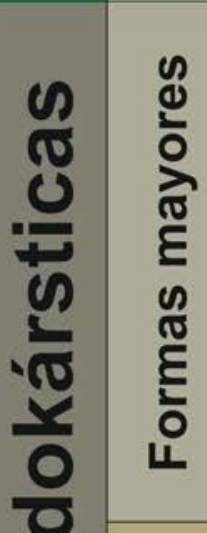 }} & Simas & $\begin{array}{c}\text { Se desarrollan a favor de } \\
\text { la estructura geológica } \\
\text { verticalizada y el } \\
\text { entrecruzamiento de } \\
\text { fallas y fracturas. } \\
\text { Alcanzan desarrollos de } \\
\text { hasta } ~ 3.500 \text { metros y } \\
\text { profundidades de hasta } \\
\text {-654 metros (explorados). }\end{array}$ & $\begin{array}{c}\text { Interior del armazón } \\
\text { calcáreo de las Ubiñas. } \\
\text { En sectores con mayor } \\
\text { potencia de las calizas, } \\
\text { como en los Güertos } \\
\text { del Diablu y en los circos } \\
\text { glaciares de mayor } \\
\text { desarrollo. }\end{array}$ \\
\hline & & Galerías y salas & $\begin{array}{l}\text { Estructuras escalonadas } \\
\text { por niveles de base y } \\
\text { discontinuidad horizontal. }\end{array}$ & $\begin{array}{c}\text { Colgadas a diferentes } \\
\text { alturas en las cavidades. }\end{array}$ \\
\hline & & Sifones & Condiciones freáticas. & $\begin{array}{c}\text { Sector distal de las } \\
\text { cavidades endokársticas. }\end{array}$ \\
\hline & 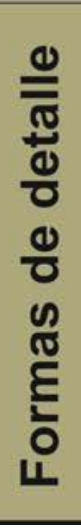 & $\begin{array}{c}\text { Estalactitas } \\
\text { Estalagmitas } \\
\text { Columnas } \\
\text { Cortinas } \\
\text { Cascadas estalagmíticas } \\
\text { Formas coraloides } \\
\text { Excéntricas } \\
\text { Gours } \\
\text { Espeleotemas subacuáticos } \\
\text { Otras morfologías } \\
\end{array}$ & $\begin{array}{l}\text { Forman conjuntos } \\
\text { integrados por } \\
\text { diversas tipologías de } \\
\text { espeleotemas. }\end{array}$ & $\begin{array}{l}\text { Alforan preferentemente } \\
\text { en galerias y salas. } \\
\text { También en abrigos } \\
\text { rocosos y en en la } \\
\text { entrada de algunas } \\
\text { cavidades. }\end{array}$ \\
\hline
\end{tabular}




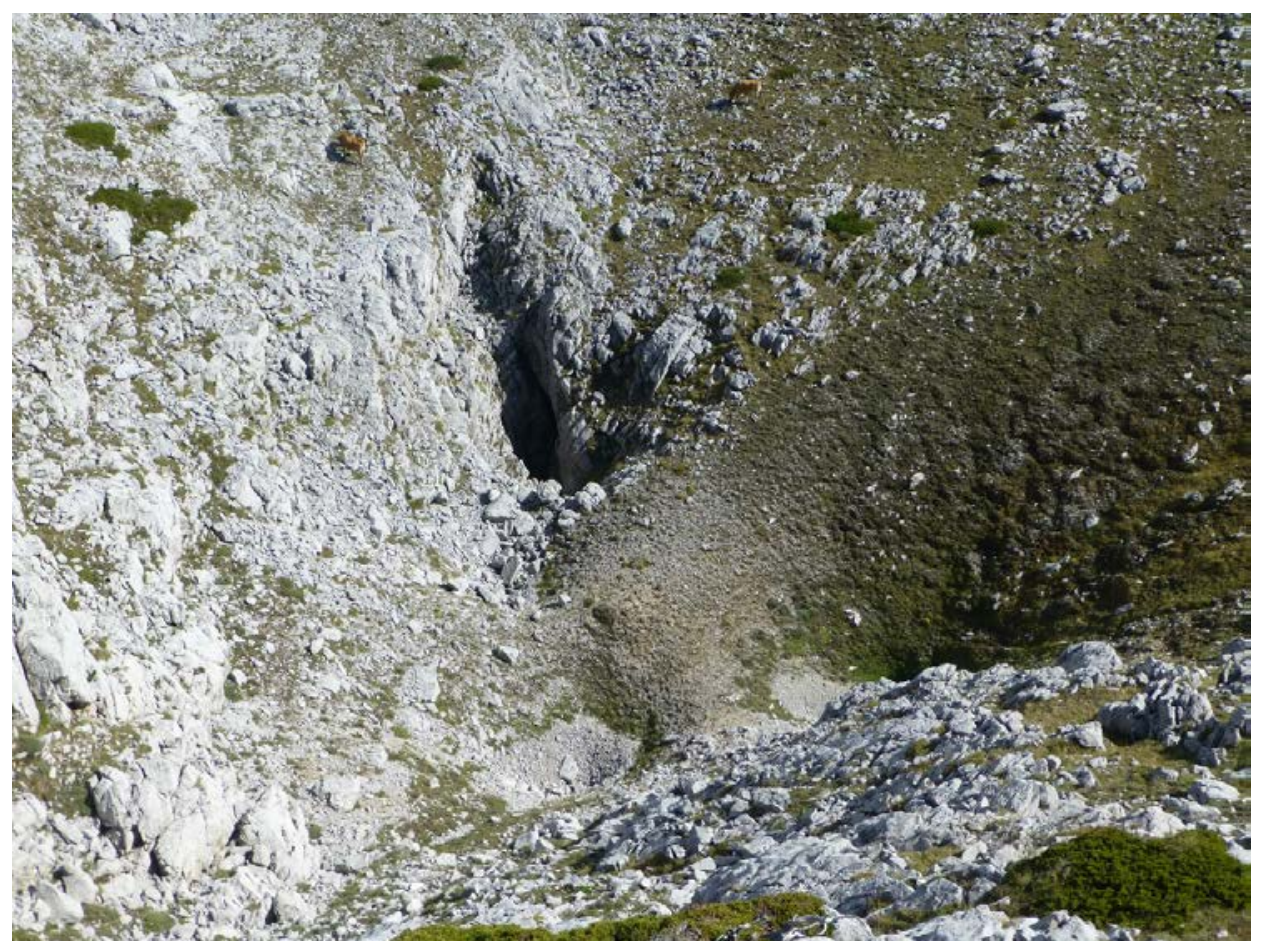

Figura 8. Depresión kárstica en la Veiga los Pozos (Güertos del Diablu). Se observan tres dolinas nivales tapizadas por derrubios y la entrada de una sima. Las vacas en la parte superior de la imagen sirven de escala $(\sim 2,5$ metros de largo).

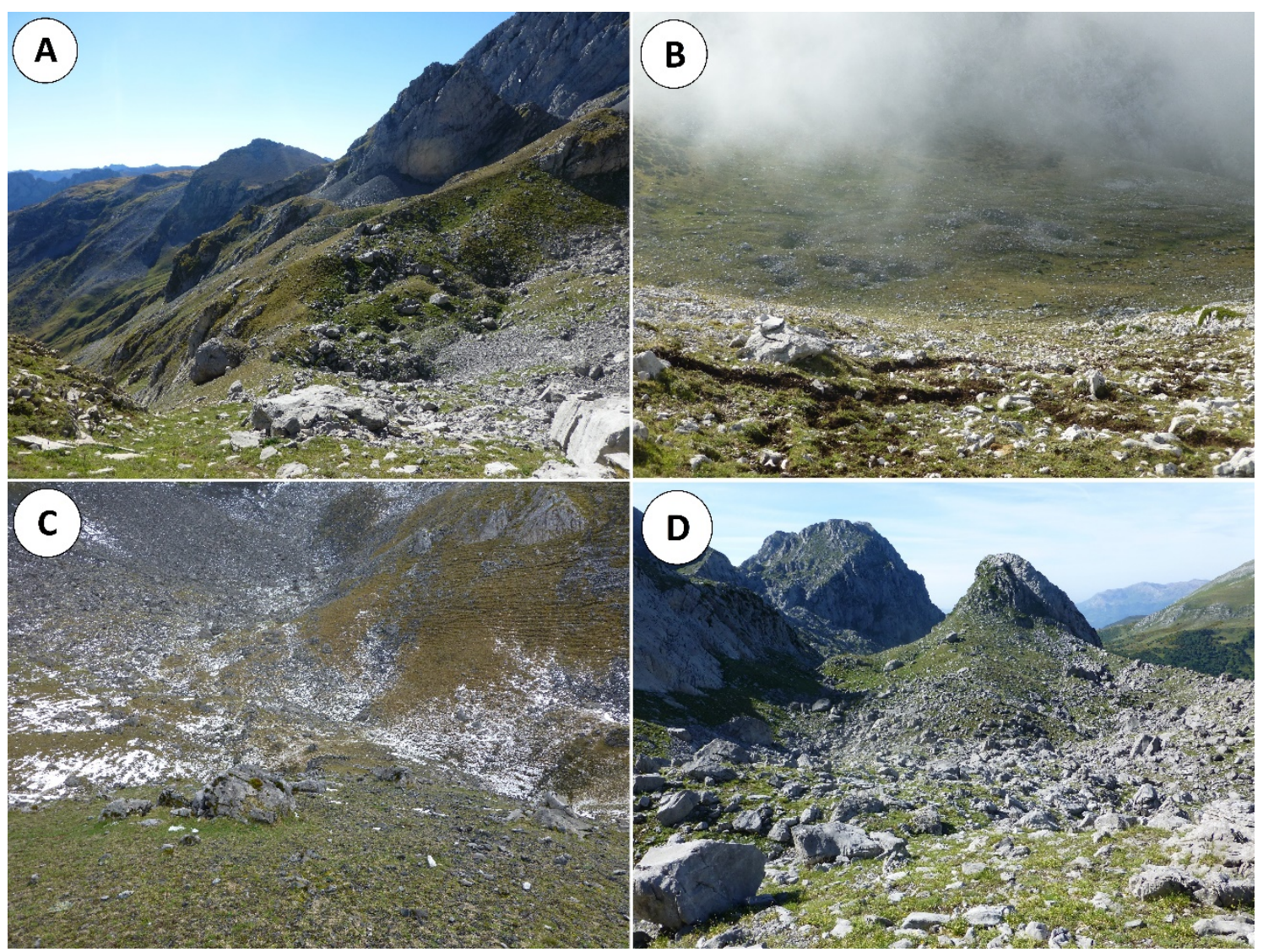

Figura 9. Fuexos en (A) El Planón, (B) la Veiga Socellares, (C) Siega l'Abá y (D) El Fuexu Llluengu. 
4.1.2.4. Simas y pozos nivokársticos. Las simas y los pozos nivokársticos (figura 10) carecen generalmente de recubrimiento superficial de arcillas de descalcificación, aunque algunos pozos pueden estar parcialmente cubiertos de derrubios. Cuentan con paredes subverticales o de gran inclinación, y su profundidad es mayor que su anchura (en el caso de las simas la longitud es notablemente superior, pudiendo alcanzar centenares de metros de desarrollo vertical y relaciones de 10 a 1 y superiores con respecto a la anchura). Así pues, estas morfologías se definen como depresiones kársticas en forma de cilindro o embudo estrecho con anchuras generalmente inferiores a 10 metros, aunque puntualmente pueden superar los 30 metros de eje mayor (figura 10); y un importante desarrollo vertical, siendo uno de los principales nexos entre el exterior y el endokarst.

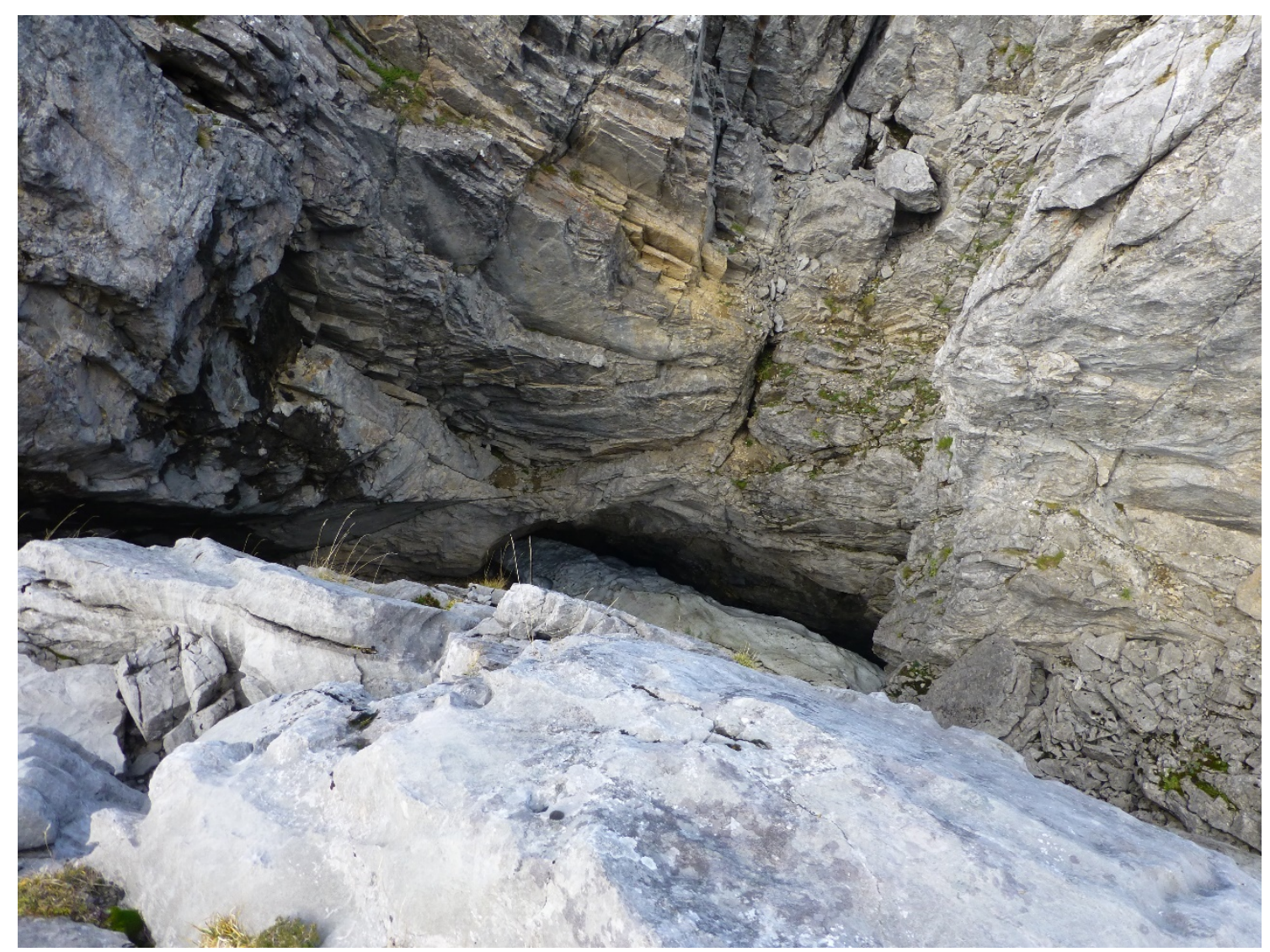

Figura 10. Sima en El Fuexu Lluengu (CCP-1). Su boca mide 32 por 10 metros y desciende 30 metros, con una galería final de 10 metros. Se aprecia nieve al fondo. Fuente: realización propia. Datos del INTERCLUB UBIÑA DEL COLECTIVU ASTURIANU D’ESPELEÓLOGOS (2013).

En las Ubiñas estas geoformas afloran mayoritariamente a partir de 1.600 metros s.n.m., aunque también existen algunas, como el Pozu la Carba (-354 metros de desarrollo vertical), en cotas inferiores. La ubicación preferente son los umbrales rocosos y las plataformas calizas (figura 10), disponiéndose ocasionalmente en paredes rocosas, como 
en Los Cinllos. En cuanto a su génesis y funcionalidad, se encuentran plenamente activas actualmente, y aprovechan las redes de debilidades estructurales para desarrollarse, ya sea por la disolución generada por las aguas de fusión nival y/o por hundimiento. Los neveros provocan la percolación de aguas de fusión hacia el interior del roquedo de forma lenta pero constante, lo que empapa las paredes y el fondo rocoso, generando una activa ablación kárstica.

4.1.2.5. Bogaces. Los corredores de disolución o bogaces (CVIJIĆ, 1893), son formas de anchuras y profundidades de orden métrico y longitudes incluso decamétricas. Se desarrollan preferentemente sobre los umbrales y superficies calizas del interior de los circos, cordales y plataformas más elevadas del macizo, como en Cuapalacio, los Güertos del Diablu y L'Estrechu. En sus paredes, además, se desarrollan en detalle diversos tipos de lapiaces, principalmente de tipo estructural y libre.

\subsubsection{Microformas exokársticas: los lapiaces}

Los lapiaces, lenares o karren, son principalmente surcos, acanaladuras y oquedades separados por aristas cuya anchura suele oscilar entre pocos milímetros y varios decímetros. Se forman debido a la disolución superficial de la caliza causada por la acción directa de flujos agua que pueden provenir de la lluvia, de la fusión nival y/o de surgencias o aguas acumuladas en las formaciones superficiales. En las Ubiñas los lapiaces proliferan en afloramientos calizos y, en menor medida, en las dolomías, especialmente si se trata de rocas descubiertas y con superficies de inclinación moderada o alta. Este es el caso de las áreas calcáreas pulidas por los paleoglaciares generados durante la Última Glaciación y sus subsecuentes fases de avances y retrocesos, así como de las paredes de los circos glaciares (figura 11), los umbrales, las cubetas glaciokársticas y las rocas aborregadas (figura 12). Aunque también abundan en las plataformas y sectores calcáreos expuestos que no fueron ocupados por el hielo glaciar.

La variedad morfológica de los lapiaces en las Ubiñas está determinada por factores debidos a las características y la estructura de la roca, como su composición, la textura, la estructura, los planos de estratificación, o la presencia de diaclasas y fracturas. Asimismo, los factores externos son igualmente importantes, destacando la pendiente de la superficie, la presencia o ausencia de suelos y de vegetación, la temperatura y su oscilación, las precipitaciones, especialmente si son en forma de nieve, o el deshielo. En función de dichos factores se pueden diferenciar tres grandes tipos de lapiaces presentes: estructurales, libres y cubiertos (tabla 2; SANTOS ALONSO y MARQUÍNEZ GARCÍA, 2005; RUIZ-FERNÁNDEZ y SERRANO, 2010; RUIZFERNÁNDEZ et al., 2019). 


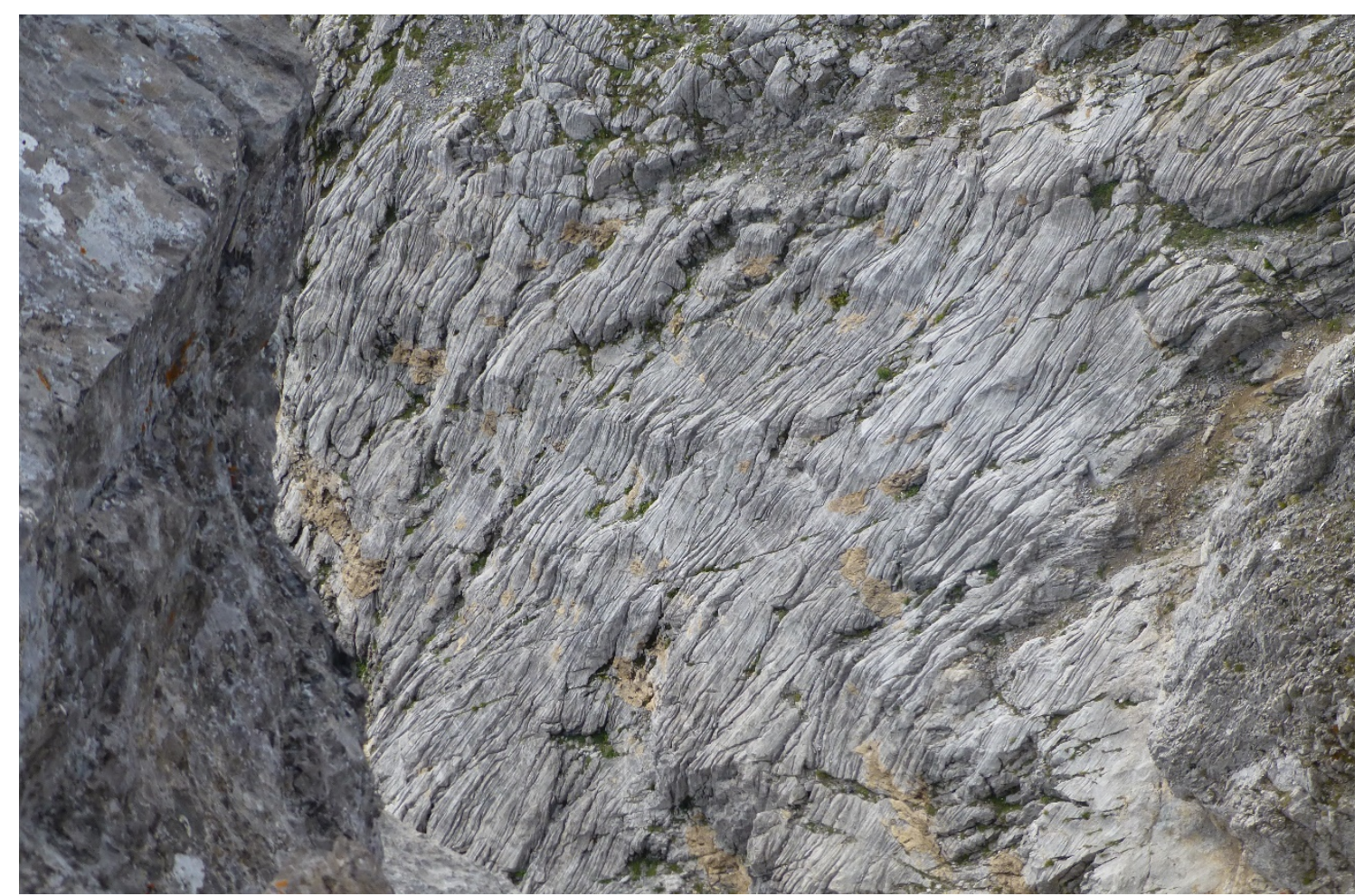

Figura 11. Ladera completamente surcada por lapiaces libres en la vertiente meridional de El Fontán Sur. Fuente: realización propia.

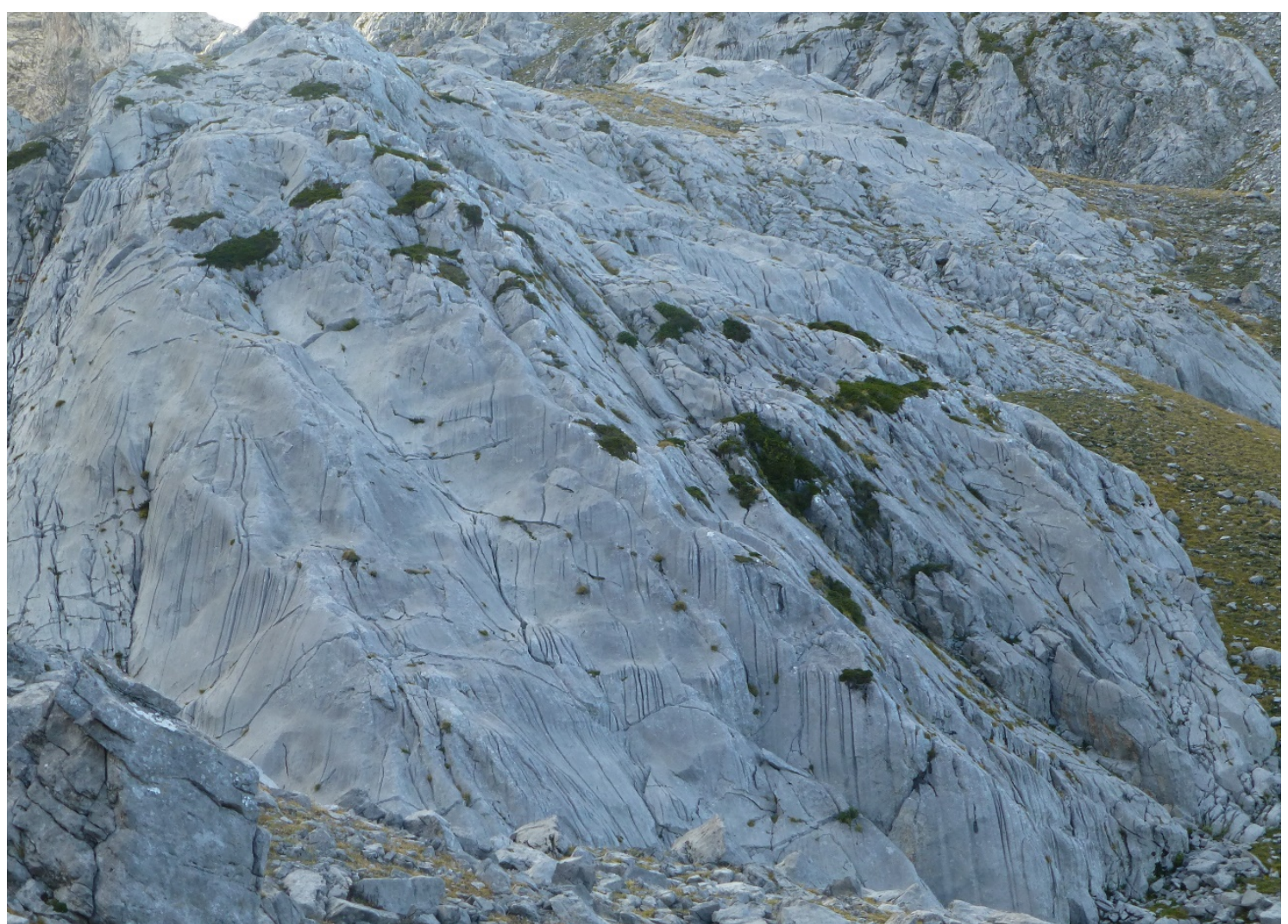

Figura 12. Superficie caliza karstificada y completamente surcada por lapiaces en el Fuexu Lluengu. Fuente: realización propia. 
4.1.3.1. Lapiaces estructurales. Los lapiaces estructurales se forman por irregularidades en la composición químico-mineralógica de la roca, así como por la existencia de discontinuidades en ella por la presencia de líneas de debilidad a través de las cuales se concentra la ablación kárstica, siendo generalmente de pequeño tamaño, de escala milimétrica a métrica (SANTOS ALONSO y MARQUÍNEZ GARCÍA, 2005). En los primeros, la intercalación de materiales de diferente naturaleza como sectores dolomíticos, venas y cristales idiomórficos de cuarzo, restos fósiles con diferente proporción de carbonato en relación a la matriz en la que yacen, laminaciones de chert, etc., provocan ritmos de disolución diferentes. Así pues, los materiales insolubles o con menor grado de solubilidad quedan en resalte, formando relieves positivos sobre la caliza, generándose microformas milimétricas a centimétricas (figura 13).

Las líneas de debilidad, como planos de estratificación, redes de diaclasas y fracturas, provocan que la disolución kárstica se vea favorecida, concentrándose y generando lapiaces estructurales de tipo fisural. En las Ubiñas es habitual encontrar niveles de calizas tableadas, lo que habilita la proliferación de estas geoformas. Los lapiaces que se generan a partir de hendiduras de pequeño tamaño, milimétrico generalmente o como mucho de escasos centímetros de anchura y longitudes milimétricas y centimétricas, se conocen como lapiaces de tipo «splitkarren», los cuales se han encontrado en la práctica totalidad de los afloramientos calcáreos del área de estudio. Si los lapiaces fisurales presentan mayor desarrollo y profundidad, llegando a adquirir anchuras de varios centímetros y longitudes métricas, se conocen como lapiaces de tipo «kluftkarren». Dichos lapiaces, también muy abundantes, implican a numerosos sistemas de discontinuidades que se entrecruzan ortogonalmente, dejando retazos de roca caliza de tamaño variable entre ellos denominados «clints». Se generan sobre superficies descubiertas y expuestas a la intemperie y bajo cubiertas edáficas.

4.1.3.2. Lapiaces libres. Son morfologías que se generan al margen de las características estructurales del roquedo calizo, debido, especialmente, al aporte de aguas de fusión nival, de ahí que su número y desarrollo aumente notablemente en las Ubiñas según se progresa en altitud. De forma generalizada, la estación del año en la que más activa se encuentra la dinámica kárstica es la primavera, pues se trata del período principal de fusión de la nieve, que se prolonga habitualmente desde marzo hasta junio. Sin embargo, en las partes más altas la fusión continúa a ritmos menores durante el verano, en torno a los neveros de fusión tardía y en las paredes y fondos de los pozos nivokársticos y simas. En estos ambientes, la disolución kárstica interactúa con la crioclastia, beneficiándose ambos procesos recíprocamente (CASTAÑÓN y FROCHOSO, 1998). 

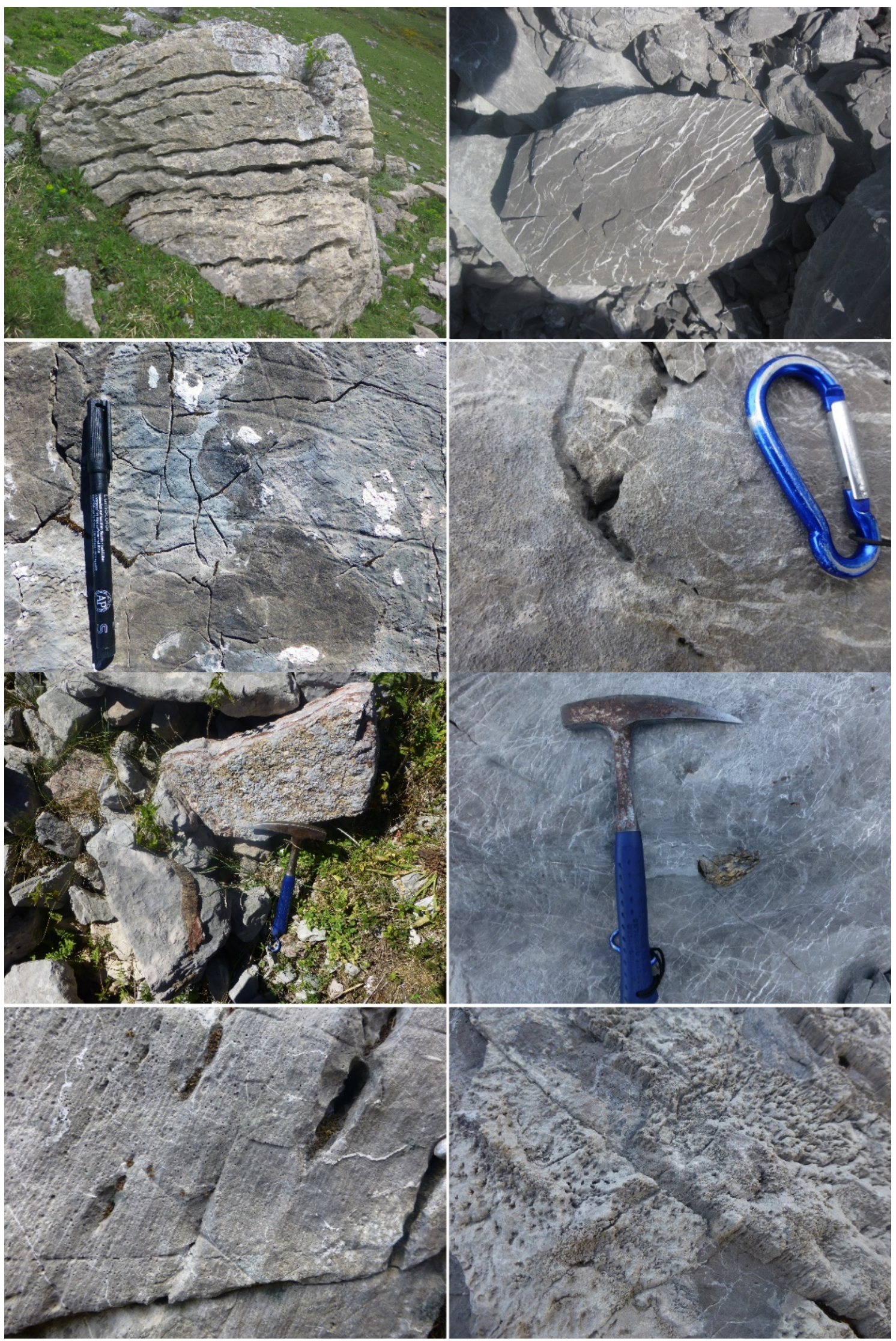

Figura 13. Lapiaces estructurales de diferentes tipos encontrados en zonas elevadas de las Ubiñas. Fuente: realización propia. 
A partir del grado de inclinación de las vertientes se generan distintas tipologías de lapiaces. Los que afloran en laderas con cierta inclinación $\left(>60^{\circ}\right)$ crean surcos agudos que se prolongan a favor de la línea de máxima pendiente y se conocen como «rillenkarren» (figura 14 A y D). Estas acanaladuras, de pocos centímetros de grosor, están separadas entre sí por crestas afiladas y tabiques, y sus longitudes pueden variar entre algunos centímetros y decenas de metros. En superficies con pendientes menores proliferan los lapiaces canalizados de sección redondeada. Estas morfologías se conocen como lapiaces de regueros o «rinnenkarren» (figura $14 \mathrm{~A} \mathrm{y} \mathrm{B).} \mathrm{Su} \mathrm{trazado} \mathrm{suele} \mathrm{ser}$ rectilíneo en pendientes $>30^{\circ}$ (lapiaces de tipo «wandkarren»), o menadriforme, cuando las pendientes son $<20^{\circ}$, siendo conocidos en este último caso como lapiaces meandriformes o «mäanderkarren» (figura $14 \mathrm{C}$ ). Los «rillenkarren» y los «rinnenkarren» proliferan especialmente en las vertientes de los umbrales molduradas previamente por los glaciares pleistocenos y en las capas inclinadas. También se pueden encontrar otros tipos de lapiaces, menos comunes, como los lapiaces de ondas o «solution ripples» y los lapiaces escalonados o «trittkarren», los cuales se desarrollan sobre superficies con escasa pendiente y son fruto de la arroyada laminar.

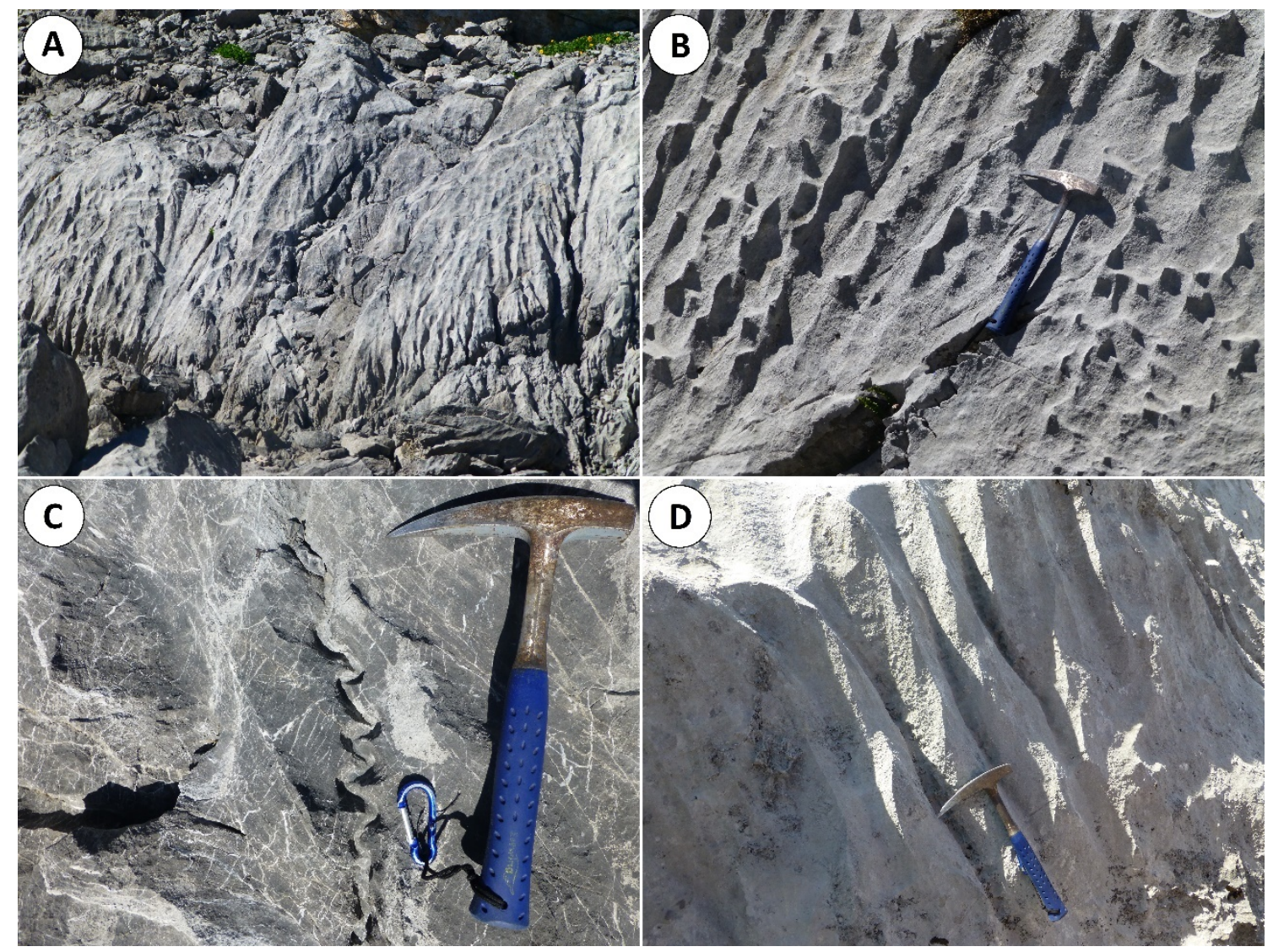

Figura 14. (A) Lapiaces de regueros en Cuapalacio. (B) Lapiaces de regueros en El Planón. (C) Lapiaz en meandro en Cuapalacio. (D) Lapiaces surcos agudos en el Fuexu Lluengu. Fuente: realización propia. 
4.1.3.3. Lapiaces cubiertos. Los lapiaces cubiertos se desarrollan a partir de la disolución provocada por aguas cargadas de $\mathrm{CO}$ y por ácidos orgánicos existentes en los suelos. Generalmente dan lugar a formas redondeadas y romas. Entre las geoformas encontradas, las más características son las cubetas de disolución, tinajitas o «kamenitzas» (figura 13 A y B) (MIOTKE, 1968; SANTOS ALONSO y MARQUÍNEZ GARCÍA, 2005; RUIZ-FERNÁNDEZ, 2013) junto a «rundkarren» y lapiaces oquerosos o «hohlkarren». Estos tipos de lapiaces son los menos comunes en las Ubiñas, de ahí que en algunos casos apenas se encontrasen ejemplares bien definidos.

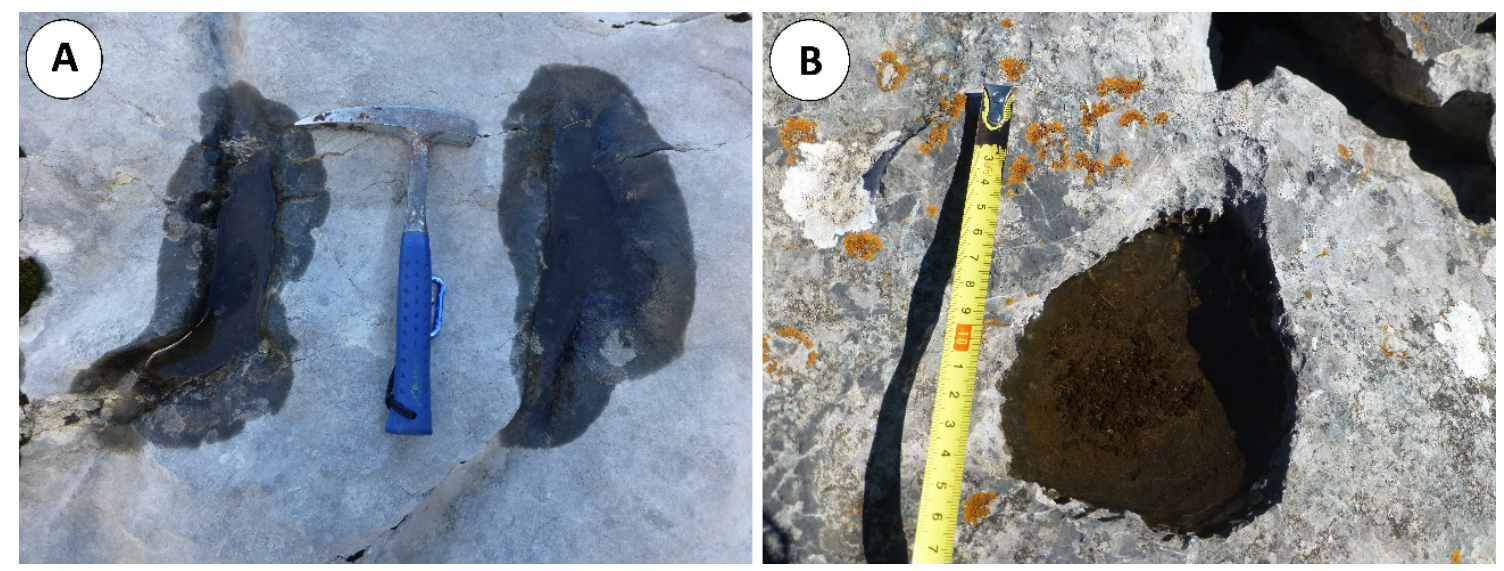

Figura 15. Cubetas de disolución en El Fuexu Ḷluengu (A) y en la Veiga Candioḷes (B). Fuente: realización propia.

Las cubetas de disolución (figura 15 A y B) suelen tener forma ovalada, con profundidades de 5-10 centímetros y diámetros de 10-30 centímetros. Se forman debido al estancamiento del agua sobre superficies con escasa o nula pendiente, principalmente bajo cubiertas edáficas, aunque también se pueden desarrollar en superficies rocosas descubiertas, como en los umbrales glaciares de los sectores con mayor elevación y en las inmediaciones de los neveros de fusión tardía. Los «rundkarren» y los lapiaces oquerosos se forman y evolucionan bajo la cubierta edáfica, si bien posteriormente pueden ser exhumados si dichos suelos son erosionados (generalmente por acción antrópica). Los primeros forman canales y surcos que individualizan morfologías abombadas y pináculos escasamente pronunciados, siendo muy poco frecuentes en el área de estudio. Por su parte, los lapiaces oquerosos progresan verticalmente en la masa caliza generando formas tubulares guiadas por el entrecruzamiento de discontinuidades, principalmente diaclasas.

\subsection{Las formas endokársticas}

La potencia que alcanzan las calizas en las Ubiñas, que por término medio es de $\sim 1.000$ metros en la vertical, si bien como ya se ha citado en determinados enclaves pueden alcanzar los 1.500 metros (TRUYOLS et al., 1982), la disposición tectónica de este macizo y el notable desnivel que se salva entre los sectores más elevados y las partes 
más deprimidas donde afloran los materiales carbonatados (entre 950 y 2.417 metros s.n.m.), han permitido el desarrollo de más de una centena de sistemas endokársticos documendos (tabla 3), contando con las cinco simas de mayor desnivel en Asturias fuera de los Picos de Europa. Asimismo, a 7 kilómetros al Noroeste del área de estudio se encuentra el Monumento Natural de Cueva Güerta, que con sus 22.338 metros de galerías exploradas es en la actualidad el sistema endokárstico conocido de mayor longitud de Asturias.

Hasta el momento se han explorado 19 cavidades endokársticas con una profundidad de al menos 100 metros, de las cuales cuatro cuentan ya con un desarrollo investigado de 1.000 metros o más (tabla 3 y figuras 16 y 17). Entre las simas de mayor profundidad destacan el Pozu los Fuexos de Cuapalacio, con -654 metros, y el Pozu'l Trabe Rolamuela (figura 16), que desciende hasta -634 metros (con un segundo ramal que profundiza hasta la cota de -626 metros; PUCH, 1998). Sin embargo, el tramo con mayor descenso vertical explorado hasta la fecha corresponde al Pozu la Carba (figura 16), con -166 metros (PUCH, 1998). Existen también tramos con caídas en diferentes conductos endokársticos que superan los 50 metros, albergados algunos de ellos en el Pozu'l Trabe Rolamuela, con un conducto cuyo desplome se prolonga 145 metros, la sima JC-1, con una entrada vertical de 110 metros (INTERCLUB UBIÑA DEL COLECTIVU ASTURIANU D’ESPELEÓlogOS, 2013), el Pozu la Cuña, en la sima JC-3, de 82 metros de caída (INTERCLUB UBIÑA DEL COLECTIVU ASTURIANU D’ESPELEÓlOGOS, 2013) y la Torca los Cinḷos, con dos tramos, uno de -90 y otro de -60 metros (BALLESTEROS, 2008). No obstante, las cavidades citadas aún poseen conductos inexplorados. Asimismo, cavidades como la Cueva'l Melluque, a la que se calculan al menos 3.500 metros de desarrollo, apenas aparecen documentadas. Más cavidades con desarrollos significativos son el Pozu'l Trabe Rolamuela (2.604 metros), la Cueva la Paré los Cinllos (1.295 metros), el Pozu los Fuexos de Cuapalacio (1.194 metros) y la Torca los Cinl! los (980 metros de desarrollo; tabla 3). En consecuencia, las cavidades endokársticas de las Ubiñas presentan una organización escalonada, alternando pozos verticales, con galerías de gran desarrollo y pendiente, y otras horizontales dispuestas a diferentes cotas altimétricas (figura 16). Es decir, el desarrollo del endokarst del macizo tiene una marcada componente vertical, sin llegar al desarrollo alcanzado por otros conjuntos como los Picos de Europa (RUIZ-FERNÁNDEZ y POBLETE, 2012).

Finalmente, cabe citar que todo el ámbito calizo de las Ubiñas está salpicado de numerosas cavidades menores, generalmente con desarrollos inferiores a 100 metros. Se distinguen aquellas cavidades endokársticas fósiles, desconectadas actualmente de las redes funcionales y colgadas en las vertientes calcáreas del macizo, de aquellas otras funcionales, bien sea a través de conductos freáticos, o bien mediante una dinámica vadosa (o ambas). En los ambientes vadosos abundan diferentes tipologías de espeleotemas como estalactitas, estalagmitas, columnas, cortinas, cascadas estalagmíticas, formas coraloides, excéntricas, gours y espeleotemas subacuáticos. También son frecuentes los desprendimientos de paneles rocosos en el interior de las 
galerías, especialmente en los conductos más amplios (galerías de mayor sección y salas), guiadas siempre por el dispositivo estructural (figura 17).

Tabla 3. Principales sistemas endokársticos explorados del Macizo de las Ubiñas

\begin{tabular}{|c|c|c|}
\hline Nombre de la cavidad & $\begin{array}{c}\text { Desnivel } \\
\text { metros }\end{array}$ & $\begin{array}{c}\text { Desarrollo } \\
\text { metros }\end{array}$ \\
\hline Pozu los Fuexos de Cuapalacio & -654 & 1.194 \\
\hline Pozu'l Trabe Rolamuela & -634 & 2.604 \\
\hline Cueva la Paré los Cinḷlos & -406 & 1.295 \\
\hline Pozu Agüeria & -370 & 1.000 \\
\hline Pozu la Carba & -354 & ----- \\
\hline La Torca los Cinl!los & -270 & 980 \\
\hline Pozu tres la Llẹera & -260 & ----- \\
\hline Pozu'l Güertu'l Diablu & -228 & ----- \\
\hline Pozu la Vaḷina'l Corru & -220 & ----- \\
\hline Pozu JC-3 & -206 & 367 \\
\hline Sima Selecta (JC-4) & -169 & 231 \\
\hline Pozu VR-2 & -149 & $\begin{array}{l}---- \\
\end{array}$ \\
\hline Pozu C-12 & -145 & ----- \\
\hline Pozu C-27 & -138 & ----- \\
\hline Pozu Garacheiru & -130 & $\begin{array}{l}---- \\
\end{array}$ \\
\hline Pozu FPF-1 & -128 & 465 \\
\hline Cueva'l Gatu Vetu & -120 & 198 \\
\hline Pozu las Merinas & -120 & ----- \\
\hline Pozu JC-1 & -110 & 148 \\
\hline Cueva'l Melluque & ----- & $\sim 3.500$ \\
\hline Cueva l'Oscuro & ----- & ----- \\
\hline Cueva Grae & ----- & ----- \\
\hline
\end{tabular}

Fuente: Federación d'Espeleoloxía del Principáu d'Asturies (http://fespasturies.com). 


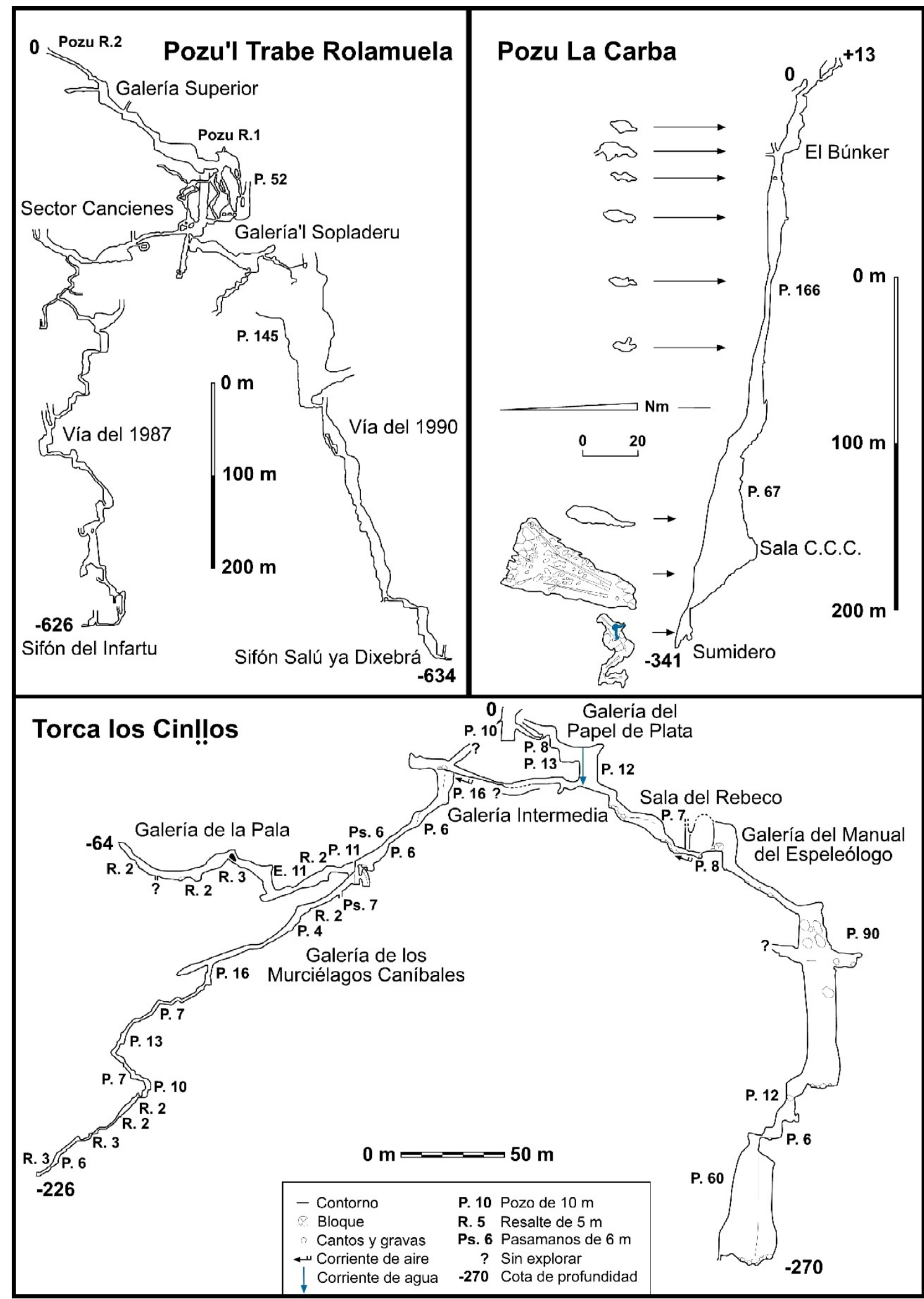

Figura 16. Cartografía en alzado de tres simas del Macizo de las Ubiñas: el Pozu'l Trabe Rolamuela, el Pozu la Carba y la Torca los Cinḷlos. Fuente: realizado a partir de PUCH (1998) y BALLESTEROS (2008). 

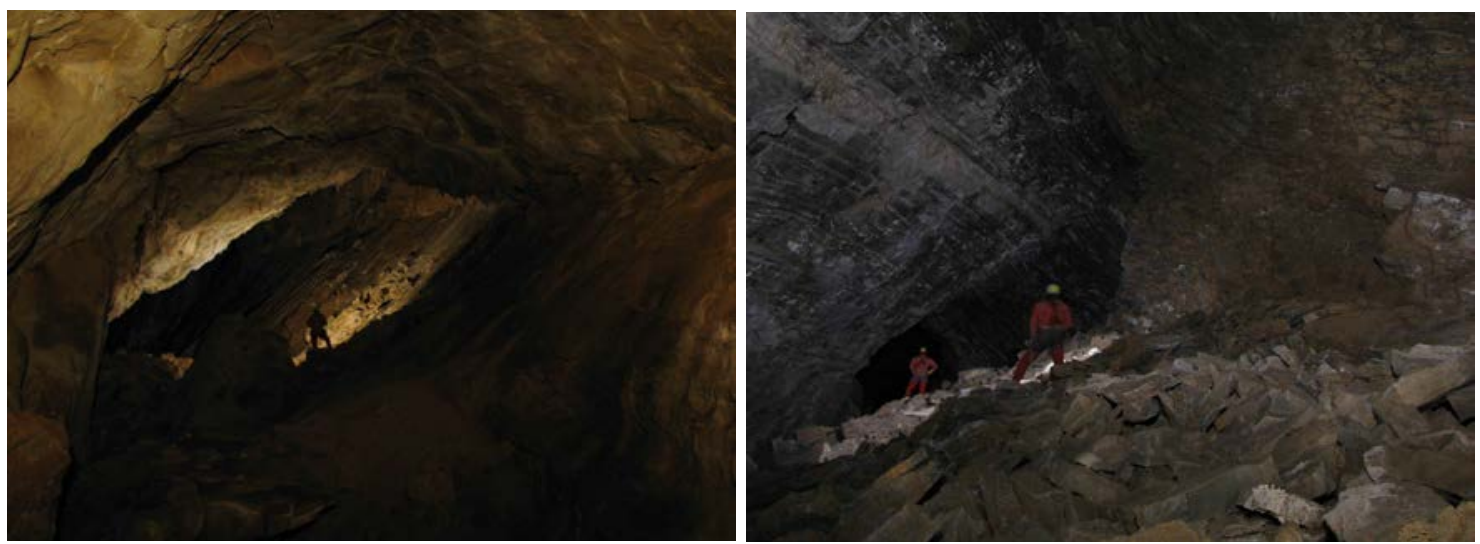

Figura 17. Interior de la Cueva la Paré los Cinllos a las cotas de -270 metros y -340 metros. Fuente: fotografías captadas por los miembros del INTERCLUB UBIÑA DEL COLECTIVU ASTURIANU D'ESPELEÓLOGOS el 10 de agosto de 2010 (izquierda) y el 25 de julio de 2009 (derecha).

La estructura geológica, el nivel de base de la red fluvial circundante, la circulación de corrientes de agua por el interior de la masa calcárea, el volumen y frecuencia de las precipitaciones, así como la existencia de materiales impermeables y el nivel freático de los acuíferos, son agentes que condicionan los procesos endokársticos, pues actúan sobre las debilidades estructurales, ahondando y profundizando las galerías por las que fluye el agua. Un buen ejemplo de cómo funciona el endokarst en las Ubiñas, así como las implicaciones del nivel freático, son el Lugar de Interés Geológico (LIG, desde 1984) de las surgencias intermitentes de Los Garrafes (figuras 18 y 19). Se trata de cuatro bocas principales que se encuentran en la vertiente septentrional del Campu Faya (1.946 metros s.n.m.) a cotas de entre 870 y 970 metros s.n.m. La intermitencia de estas surgencias se debe a la evolución de los niveles freáticos, pues cuando se encuentran saturados de agua, principalmente debido al aporte de aguas de fusión nival procedentes de la plataforma calcárea de los Güertos del Diablu y de la Veiga Soceḷares, Los Garrafes emiten abundante caudal (no se conoce la cifra exacta de $\mathrm{m}^{3} / \mathrm{s}$ ), anegando incluso los prados y caminos próximos. Sin embargo, durante los períodos secos Los Garrafes cesan su evacuación de agua debido al descenso de los niveles freáticos (figura 18).

Aunque Los Garrafes son las surgencias más conocidas de las Ubiñas, existen otras repartidas por el área de estudio como El Nacimientu (El Puerto Güeria), El Fontán (sector leonés de Penubina), La Salú (El Puerto Güeria), y Vallao (al Norte del refugio de El Meicín; figura 1). No obstante, en estos casos se trata de surgencias que no interrumpen su flujo de agua, ni siquiera durantre el estío. Todas ellas se encuentran en zonas de altitudes medias y bajas dentro del ámbito de las Ubiñas, sin encontrar ninguna por encima de 1.900 metros s.n.m. 


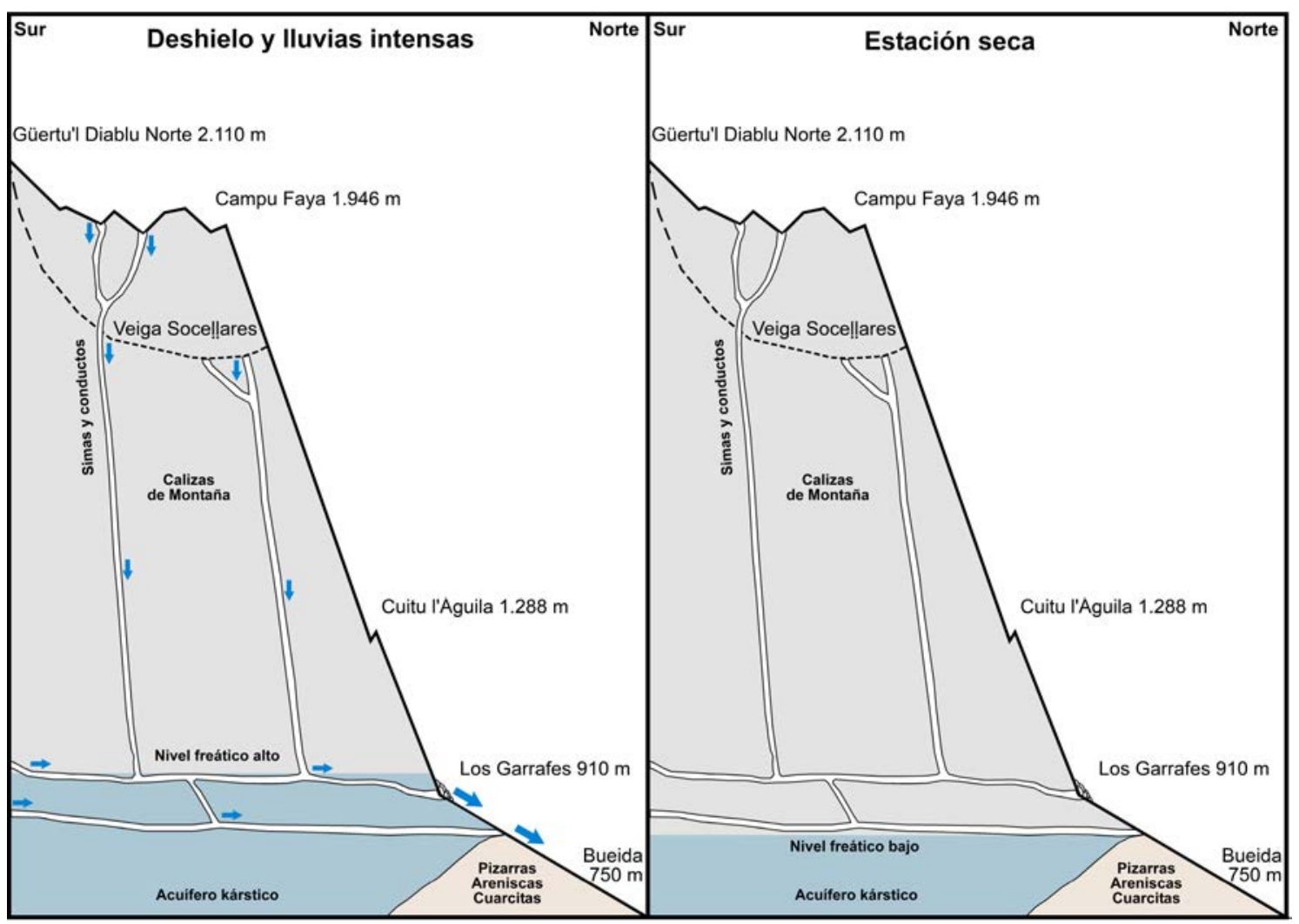

Figura 18. Esquema del funcionamiento interior de las surgencias estacionales de Los Garrafes. Fuente: elaboración propia.
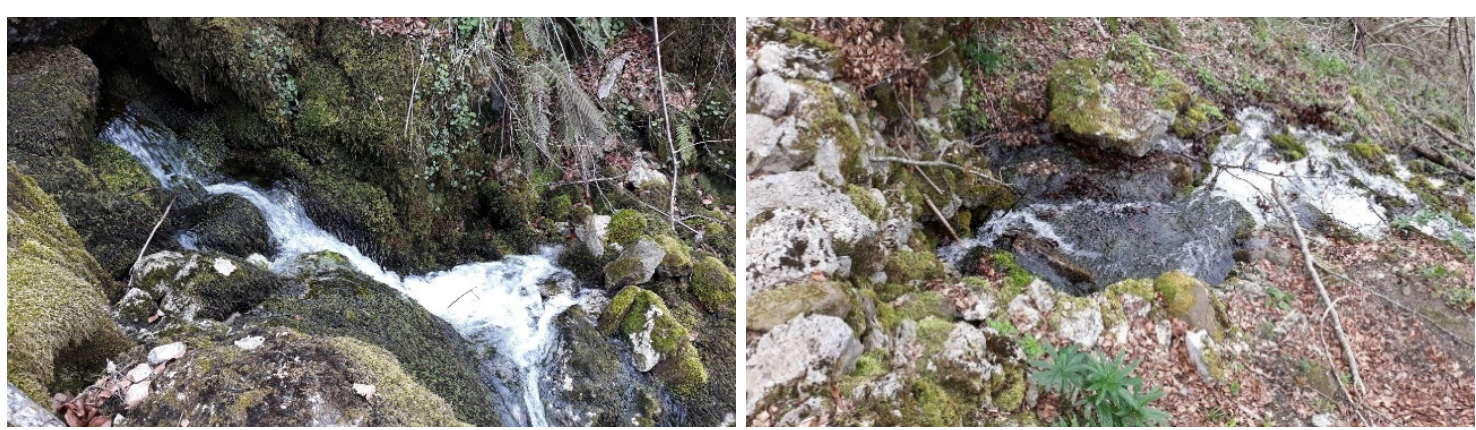

Figura 19. Los Garrafes con un caudal de agua escaso. A la izquierda El Garrafe Viechu. A la derecha La Fontona. Fuente: realización propia.

\section{DISCUSIÓN}

\subsection{La interrelación entre el karst y el modelado glaciar}

El karst en las Ubiñas estuvo y continúa estando fuertemente condicionado por los procesos fríos. Concretamente, el macizo estuvo ocupado por 20 glaciares durante la fase de Máxima Expansión del Hielo (MEH) dentro de la Última Glaciación. Estos glaciares experimentaron hasta tres grandes fases en su evolución (la ya mencionada fase de MEH, la fase interna y la fase de altitud; GALLINAR et al., 2014), escindiéndose en masas menores a la par que fueron retrocediendo entre unas fases y 
otras. En consecuencia, la karstificación necesariamente ha experimentado relaciones de interferencia e interdependencia con el glaciarismo cuaternario de las Ubiñas.

Sin lugar a dudas, el relieve kárstico preglaciar condicionó el flujo y la dinámica de las masas de hielo. De esta manera, la topografía intrincada y escabrosa propia de los ámbitos kársticos provocó que, en su retroceso, los glaciares experimentasen una dinámica entrecortada, debido a la frecuente interposición de grandes cubetas glaciokársticas escalonadas y separadas por umbrales. En este sentido, al igual que ha sido señalado por diversos autores en el caso de los Picos de Europa (MIOTKE, 1968; CASTAÑÓN y FROCHOSO, 1994), esto favoreció la acumulación de material morrénico rellenando el fondo de las depresiones glaciokársticas y adosado a sus bordes, así como sobre algunos umbrales, debido en muchas ocasiones a la dinámica típica glaciokárstica, y no necesariamente a pulsaciones climáticas (RUIZFERNÁNDEZ et al., 2019).

A su vez, el relieve kárstico previo a la Última Glaciación fue sustancialmente modificado a causa la abrasión y sobreexcavación generada por flujo del hielo. Hemos de tener en cuenta que los sectores de altitud media y baja de las Ubiñas no son carbonatados, por lo que apenas hay espacios calizos por debajo de las áreas que estuvieron glaciadas, en los que se conserven morfologías kársticas preglaciares. No ocurrió lo mismo en otros grandes macizos cantábricos cercanos como los Picos de Europa, integrados casi exclusivamente por calizas. En ellos los sectores situados por debajo de los frentes glaciares conservan un karst cubierto de tipo oceánico caracterizado por una rica morfología, entre la que cabe destacar la abundancia de los lapiaces en torrecillas, que en cambio fueron descabezados en las áreas ocupadas por el hielo glaciar (RUIZ-FERNÁNDEZ et al., 2019).

Por otra parte, las depresiones kársticas preexistentes, que en la alta montaña constituyeron enclaves muy favorables para la acumulación de nieve y su transformación en hielo, se vieron ampliamente remodeladas por la sobreexcavación glaciar, generándose finalmente las grandes hoyas de génesis mixta incluidas en la tabla 1 .

El endokarst y los flujos de agua subterráneos también se vieron afectados por el glaciarismo, ya que el drenaje, previamente difuso, se concentró en algunas cavidades, las cuales, al mismo tiempo, aumentaron en desarrollo, anchura y profundidad ante los aportes de las voluminosas corrientes de agua subglaciares. Los cursos subglaciares posiblemente fueron capaces de abrir nuevos conductos. Por contraposición, la progresiva retirada del hielo hasta la completa deglaciación del macizo, modificó las condiciones de drenaje nuevamente, pasando a ser difusa. A su vez, los afloramientos rocosos quedaron nuevamente expuestos a la meteorización, lo que auspició la aparición de lapiaces que actualmente siguen desarrollándose (principalmente lapiaces libres; MIOTKE, 1969; GONZÁLEZ-TRUEBA, 2006; RUIZ-FERNÁNDEZ, 2013). De esta manera, las morfologías glaciares de detalle, como las estrías y acanaladuras, desaparecieron de toda superficie a la intemperie en las Ubiñas, aunque aún pueden encontrarse en cantos y bloques que quedaron protegidos por el till de la meteorización. 


\subsection{La interrelación entre el karst y el modelado periglaciar y nival}

Durante la Última Glaciación, el cinturón periglaciar se extendía por debajo del área glaciada, incluyendo también sectores altos libres de hielo. A medida que los glaciares fueron retrocediendo hasta su completa desaparición, el cinturón periglaciar fue ascendiendo en altitud, hasta ocupar actualmente una franja comprendida entre los 1.800 metros s.n.m. y las cumbres más altas, diferenciándose netamente dos sectores dentro de ella, i) el área nivoperiglaciar (1.800-2.200 metros s.n.m.; RODRÍGUEZ PÉREZ, 1995; SERRANO y GONZÁLEZ-TRUEBA, 2004; RUIZ-FERNÁNDEZ et al., 2014), definida por un periglaciarismo atenuado, vinculado principalmente con los procesos nivales (aludes, fusión estacional del manto nival y procesos asociados) y con una acción de la crioclastia limitada, y ii) el área crionival (por encima de 2.200 metros s.n.m.), caracterizada por una mayor efectividad de la gelifracción y por la existencia de procesos como la crioturbación (BROSCHE, 1978; CASTAÑÓN y FROCHOSO, 1994, 1998; SERRANO y GONZÁLEZ-TRUEBA, 2004; GONZÁLEZ-TRUEBA, 2006; PELLITERO, 2012; GALLINAR et al., 2014; RUIZ-FERNÁNDEZ et al., 2014, 2016, 2017). Consecuentemente, también se dan importantes interferencias y relaciones de interdependencia entre la dinámica periglaciar y nival de las partes altas de la Ubiñas, y la disolución kárstica.

De hecho, el karst que se desarrolla en los sectores de mayor altitud (por encima de 1.700 metros) es de tipo nival (MAIRE, 1984), al generarse en un enclave montañoso donde las precipitaciones son superiores a $1.500 \mathrm{~mm}$, e incluso a $2.000 \mathrm{~mm}$ en los ámbitos más elevados, donde además gran parte se producen en forma de nieve, y en el que las temperaturas medias son bajas, como ya se ha especificado. En este sentido, la nieve en las Ubiñas genera un manto continuo durante más de 6,5 meses en altitudes de 1.800 a 2.000 metros s.n.m. e incluso de hasta 8 meses a 2.400 metros s.n.m., llegando a pervivir neveros individualizados en algunos casos todo el año. Este tipo de condiciones ambientales son muy propicias para el desarrollo de la karstificación, dando lugar a morfologías bien definidas y de evolución rápida, debido a la abundancia de aguas frías de fusión nival, que se tornan muy agresivas para las calizas ante gran capacidad de absorción de $\mathrm{CO}_{2}$ del aire bajo las condiciones térmicas señaladas. En consecuencia, las tasas de karstificación propias de los ambientes nivales son muy altas, como han registrado GARAY y MORREL (1989) en el caso de los Picos de Europa, con entre 100 y $148 \mathrm{~m}^{3} / \mathrm{km}^{2} /$ año.

A su vez, en estos ámbitos los ciclos de hielo-deshielo afectan a las superficies expuestas (ej. paredes y crestas), de tal manera que la acción de la crioclastia es eficaz (no ocurre lo mismo en las superficies rocosas y formaciones superficiales cubiertas por el manto nival, en las que el impacto de los ciclos de hielo-deshielo es menor al quedar una situación de homotermia, aisladas de las fluctuaciones diarias de la temperatura del aire hasta que acontece la fusión estacional; SERRANO y GONZÁLEZ-TRUEBA, 2004; GONZÁLEZ-TRUEBA, 2006; PELLITERO, 2012; RUIZ-FERNÁNDEZ, 2013; RUIZ-FERNÁNDEZ et al., 2014, 2017, 2019; PISABARRO et al., 2017). Además, la 
disolución kárstica se combina habitualmente con la crioclastia, retroalimentándose mutuamente, pues la primera incide en las rocas, generando abundantes oquedades fácilmente atacables por la segunda, y viceversa (NICOD, 1972; CASTAÑón y FROCHOSO, 1998). Esta interferencia entre ambos procesos es lo que Maire (1990) denomina gelidisyunción. En este sentido, CASTAÑÓN y FROCHOSO (1998), describen morfologías derivadas de la gelidisyunción y la gelidescamación en los Picos de Europa.

\subsection{Las etapas en la evolución del relieve kárstico de las Ubiñas}

El modelado kárstico de las Ubiñas se ha conformado a lo largo de un extenso periodo temporal en el que alternaron condiciones climáticas contrastadas, pues, con toda probabilidad, la karstificación del macizo comenzó a producirse con su levantamiento. Así pues, pueden distinguirse hasta tres grandes etapas en la evolución del karst de estas montañas a partir de las morfologías y vestigios encontrados: una preglaciar, una glaciar, y una postglaciar, más cálida que la anterior y caracterizada por el retoque de las formas previas bajo condiciones periglaciares y nivales. Sin embargo, por el momento no es posible aportar datos geocronológicos ni una evolución precisa, pues el exokarst de las Ubiñas no había sido estudiado hasta esta contribución, y la información disponible sobre el endokarst es aún exigua, contrastando con la existente en cambio sobre otros conjuntos montañosos próximos como los Picos de Europa, que cuentan con una larga e importante tradición espeleológica y con investigaciones científicas específicas (ej. SENIOR, 1987; BALLESTEROS et al., 2011, 2015, 2019; RUIZFERNÁNDEZ y POBLETE, 2012; GÓMEZ-LENDE, 2015; BALLESTEROS, 2016).

Karst preglaciar: Como testimonios de las primeras fases de karstificación, se conservan distintos niveles de galerías fósiles en las cavidades endokársticas estudiadas, que junto a condicionantes estructurales, evidencian a su vez distintos niveles de base en el proceso de encajamiento de la red fluvial circundante. También pertenecen a esta primera fase las grandes depresiones exokársticas, que fueron retrabajadas posteriormente por los glaciares.

Karst glaciar: En esta segunda etapa se desarrollaron potentes y extensas masas de hielo que retrabajaron las grandes depresiones kársticas preexistentes, ensanchándolas y profundizándolas, y borraron las formas kársticas previas de escala media y pequeña. Las principales fases de avance dentro de la Última Glaciación cuentan con cronologías en las Montañas Cantábricas comprendidas entre 45 y 11,6 ka (MORENO et al., 2010; SERRANO et al., 2012, 2013; JIMÉNEZ et al., 2013; PELLITERO, 2013; RUIZFERNÁNDEZ et al., 2016, 2022; RODRÍGUEZ-RODRÍGUEZ et al., 2016, 2017; RUIZ-FERNÁNDEZ y GARCÍA-HERNÁNDEZ, 2018). Sin embargo, en los últimos años han visto la luz estudios que proponen fases glaciares más antiguas, con edades de 170-150 (MIS 6) y 110 ka (MIS 5d; RODRÍGUEZ-RODRÍGUEZ et al., 2016, 2018), y 78-65 ka (MIS 4; FROCHOSO et al., 2013). Necesariamente, el drenaje hacia el interior del macizo calizo pasó de ser difuso (canalizado a través de la densa red de discontinuidades de diferente escala existentes en las calizas), a concentrado en muchos 
menos puntos situados preferentemente en el fondo de las depresiones glaciokársticas y también en los umbrales, por los que se infiltraban los cauces subglaciares. Esto contribuyó a desarrollar aún más algunas de las cavidades endokársticas preexistentes, y generó nuevos conductos. Por su parte, muchos otros quedaron taponados por sedimentos glaciares o por el propio hielo. Durante las fases glaciares en los Picos de Europa ha sido propuesta una dinámica similar (MIOTKE, 1968; SMART, 1984, 1986; SENIOR, 1987; ROSSI, 2004, VERHAYDEN et al., 2007; RUIZ-FERNÁNDEZ y SERRANO, 2011; RUIZ-FERNÁNDEZ et al., 2019).

Karst postglaciar o actual: Esta fase se desarrolló principalmente en el Holoceno, y continúa activa actualmente. Tras las etapas glaciares, el drenaje de las escorrentías volvió a ser difuso, al quedar expuestas nuevamente las superficies calizas. Éstas han sido profusamente retocadas, borrando las microformas de erosión glaciar (estrías y acanaladuras), y generando campos de lapiaz y nuevas dolinas y pozos nivales en el fondo de las depresiones glaciokársticas y en los umbrales, así como fuexos, estos últimos a favor de los mantos de till y derrubios de vertiente que recubren parcialmente algunas de las depresiones y barras de caliza. Las escorrentías captadas en las partes elevadas del macizo son canalizadas hacia la red de surgencias generadas en el contacto entre las calizas y los materiales impermeables de las partes bajas y medias del macizo, propiciando que el desarrollo del endokarst continúe, tanto en condiciones freáticas como vadosas.

\subsection{La organización altitudinal de las formas kársticas en las Ubiñas}

Dependiendo de la altitud y de las condiciones topoclimáticas y orográficas de cada sector de las Ubiñas, se pueden diferenciar hasta tres ámbitos kársticos diferentes: la franja inferior, con mayor influencia vegetal y edáfica; un área de desierto kárstico; y una franja de influencia nival propia de los sectores de mayor altitud.

Franja kárstica inferior: Se desarrolla generalmente por debajo de 1.700 metros s.n.m.; es decir, es la que ocupa los sectores medios y distales de los glaciares durante las fases de MEH e interna de la Última Glaciación. Se trata de ámbitos donde existen suelos con cierto desarrollo, generalmente a favor de mantos, cordones y arcos morrénicos, y la vegetación forma tapices herbáceos y/o matas de arbustos de porte bajo. La influencia nival en el desarrollo del karst es más atenuada que en los otros dos sectores definidos. Asimismo, abundan las surgencias asociadas a los frentes glaciares o a cambios litológicos. Pese a ser la franja con mayor desarrollo de los suelos, los lapiaces cubiertos son poco abundantes, debido a la escasa extensión de los afloramientos calizos en las partes bajas y medias del Macizo de las Ubiñas, que fueron las que estuvieron al margen de la erosión protagonizada por los glaciares pleistocenos. Por otra parte, a mayores cotas, la escasez de suelos (salvo puntualmente en los ámbitos recubiertos por material morrénico y derrubios periglaciares), impide igualmente el desarrollo de lapiaces de tipo cubierto. En cambio, en los ámbitos de baja y media montaña de otros sectores con mayor extensión de las calizas, como los Picos de Europa, se desarrolla un karst cubierto templado en el que abunda este tipo de lapiaces 
y, además, se conservaron las formas previas a la Última Glaciación, que a mayor cota fueron borradas (RUIZ-FERNÁNDEZ y SERRANO, 2011; RUIZ-FERNÁNDEZ et al., 2019).

Sector del desierto kárstico: En las Ubiñas está presente en un sector concreto, el correspondiente a la parte culminante de la plataforma de los Güertos del Diablu (figura 20). Aquí apenas se han desarrollado suelos, que en el mejor de los casos cabría calificar de litosuelos o suelos muy incipientes, la cubierta vegetal es muy exigua (cuando existe), y prácticamente no hay depósitos superficiales de entidad. Así pues, existe un predominio casi absoluto de la roca caliza al descubierto y de los procesos de ablación kárstica y de percolación de las escorrentías hacia el interior del macizo de forma difusa, a través de la red de discontinuidades estructurales, que han guiado también el desarrollo de dolinas y simas. En este ámbito, la influencia nival en el desarrollo del karst es evidente. Este término, tomado de NICOD (1972), fue aplicado por RUIZ-FERNÁNDEZ (2013) y RUIZ-FERNÁNDEZ et al. (2019) para denominar una de las franjas kársticas definidas en el Macizo Occidental de los Picos de Europa.

Franja de karst nival: se trata de la última área kárstica y la más elevada, desarrollándose a partir de 1.700 metros s.n.m., en el entorno de los circos glaciares, vertientes, crestas y puntos más elevados del macizo. En estos ambientes los suelos son escasos e incipientes, por lo que la disolución actúa esencialmente sobre la roca desnuda, generando pozos nivokársticos, fuexos y diferentes tipologías de lapiaces libres entre las que abundan principalmente los «rillenkarren» y los «rinnenkarren». La nieve perdura hasta 8 meses y abundan los neveros de fusión tardía, lo que asegura copiosos aportes de aguas de fusión que efectúan una intensa labor de disolución y una rápida evolución de las formas kársticas (especialmente de los lapiaces libres).

\section{CONCLUSIONES}

El karst de Las Ubiñas ha evolucionado a través de una sucesión de tres etapas. Una primera etapa anterior al desarrollo del glaciarismo cuaternario, una segunda etapa glaciar, y una postglaciar más cálida que la precedente, caracterizada por la influencia nival, que se ha venido desarrollando durante el Holoceno. En la actualidad, el importante desarrollo altitudinal y el régimen climático, con elevadas precipitaciones en forma de nieve, y pervivencia de los neveros durante los meses estivales en los sectores más altos, favorecen un karst nival con altas tasas de disolución. Si bien, dichos procesos y sus morfologías resultantes son distintos en función de la altitud, pudiendo diferenciar hasta tres sectores kársticos: la franja kárstica inferior, por debajo de 1.700 metros s.n.m., con mayor desarrollo edáfico y vegetal, así como limitada influencia nival; el área de desierto kárstico, circunscrito a la plataforma de los Güertos del Diablu, actualmente sin desarrollo edáfico significativo ni vegetación, $\mathrm{y}$ dominado principalmente por los procesos kársticos; y una franja de karst nival, a partir de 1.700 metros s.n.m. 


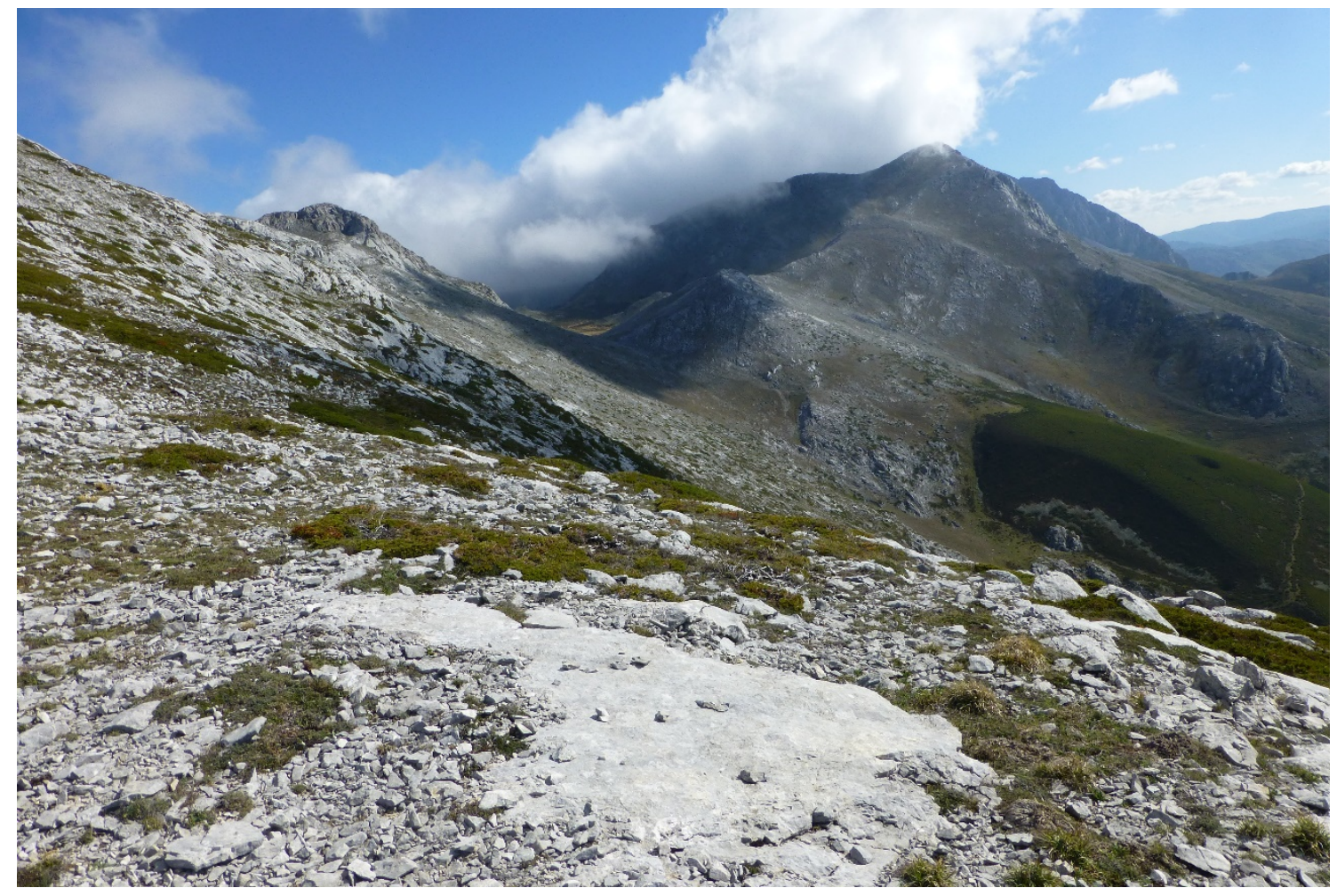

Figura 20. Desierto kárstico en la parte culminante de la plataforma de los Güertos del Diablu. Fuente: realización propia.

En Las Ubiñas, la karstificación ha experimentado relaciones de interferencia con otros procesos y formas del relieve, siendo el glaciarismo cuaternario el más destacado de ellos. El relieve kárstico preglaciar condicionó el flujo de las masas de hielo $\mathrm{y}$, a su vez, fue sustancialmente modificado a causa de la abrasión $\mathrm{y}$ sobreexcavación glaciar. De hecho, apenas se conservan morfologías kársticas previas, ya que casi no hay espacios calizos por debajo de las áreas que estuvieron glaciadas. Del mismo modo, la karstificación ha hecho desaparecer las morfologías glaciares de detalle. Las cubetas glaciokársticas, única forma exokárstica mayor presente, generalmente por encima de 1.700 metros s.n.m., constituyen un buen ejemplo de dicha interacción debido a su génesis mixta. Estas han experimentado rellenos sedimentarios de diversa génesis, destacando los de origen glaciar en las partes medias y bajas, mientras que a mayores altitudes albergan derrubios tanto glaciares como periglaciares.

A las macroformas mencionadas, se añaden mesoformas como las dolinas y uvalas, tapizadas por derrubios y arcillas de descalcificación, dolinas de recubrimiento asociadas a recubrimientos de origen glaciar, periglaciar, torrencial y lacustre, simas y pozos nivokársticos que afloran a partir de 1.600 metros s.n.m., y bogaces, especialmente en el interior de los circos glaciares. Asimismo, en Las Ubiñas proliferan las microformas exokársticas, entre las que destacan los lapiaces libres y estructurales, favorecidos estos últimos por la abundancia de niveles de calizas tableadas, y siendo mucho menos común encontrar lapiaces cubiertos. 
Finalmente, el endokarst y los flujos subterráneos también se vieron afectados por el glaciarismo, ya que el drenaje, previamente difuso, se concentró en algunas cavidades, volviendo a ser difuso tras la retirada de los hielos. La potencia que alcanzan las calizas en Las Ubiñas, junto con el notable desnivel, han propiciado el desarrollo de más de un centenar de sistemas endokársticos con una marcada componente vertical, llegando a superar en varios casos los 1.000 metros de desarrollo, aunque sin alcanzar el desarrollo observado en otros conjuntos montañosos cantábricos, como los Picos de Europa.

\section{Agradecimientos}

Esta contribución aborda parte de los temas de investigación tratados en el proyecto de investigación PID2020-115269GB-I00 (MICINN, Gobierno de España).

\section{BIBLIOGRAFÍA}

Adrados González, L., 2011. Costa oriental de Asturias. Un paisaje singular. Adrados Ediciones, Oviedo/Uviéu.

Aller, J., 1984. La estructura del sector meridional de las unidades del Aramo y Cuenca Carbonifera Central. Servicio de Publicaciones del Principado de Asturias, Consejería de Industria y Comercio. Oviedo/Uviéu.

Alonso, J.L., García Alcalde, J.L., Aramburu, C., García Ramos, J.C., Suárez, A., Martínez Abad, I, 2008. Sobre la presencia de la Formación Naranco (Devónico Medio) en el Manto de Bodón (Zona Cantábrica): implicaciones paleogeográficas. Trabajos de Geología, 28. 159-169.

Álvarez Cañada, A., 1997. Estudio geomorfológico de la sierra de Peña Mea (Cordillera Cantábrica). Ería, 44. 261-279. https://doi.org/10.17811/er.0.1997.261-279

Artugyan, L., 2017. Geomorphosites Assessment in Karst Terrains: Anina Karst Region (Banat Mountains, Romania). Geoheritage, 9. 153-162. https://doi.org/10.1007/s12371-016-0188$\mathrm{x}$

Ballesteros, D., 2008. A Torca de los Cinchos sae do esquecemento. Montañeiros Celtas, 96. 46-47.

Ballesteros, D., 2016. Geomorfología y evolución de cuevas alpinas en los Picos de Europa, Cordillera Cantábrica (España). Tesis Doctoral. Universidad de Oviedo. Oviedo/Uviéu.

Ballesteros, D., Giralt, S., García-Sansegundo, J., Jiménez-Sánchez, M., 2019. Quaternary regional evolution based on karst cave geomorphology in Picos de Europa (Atlantic Margin of the Iberian Peninsula). Geomorphology, 336. 133-151. https://doi.org/10.1016/j.geomorph.2019.04.002

Ballesteros, D., Jiménez-Sánchez, M., García-Sansegundo, J., Giralt, S., 2011. Geological methods applied to speleogenetical research in vertical caves: the example of Torca Teyera shaft (Picos de Europa, northern Spain). Carbonates and Evaporites, 26 (1). 29-40. https://doi.org/10.1007/s13146-011-0052-7

Ballesteros, D., Jiménez-Sánchez, M., Giralt, S., García-Sansegundo, J., Meléndez-Asensio, M., 2015. A multi-method approach for speleogenetic research on alpine karst caves. Torca La 
Texa shaft, Picos de Europa (Spain). Geomorphology, $247 . \quad 35-54$. https://doi.org/10.1016/j.geomorph.2015.02.026

Barea Luchena, J., 2001. Geomorfología y evolución paleoclimática durante el Cuaternario aa partir del estudio de los macizos kársticos de los bordes del Sistema Central y de Valporquero, León. Universidad Complutense de Madrid, Servicio de Publicaciones.

Bögli, A., 1980. Karst Hydrology and Physical Speleology, Berlin - New York, Springer Verlag.

Brosche, K.U., 1978. Formas actuales y límites inferiores periglaciares en la Península Ibérica. Estudios Geográficos, 151.131-161.

Castañón, J.C., 1983. El glaciarismo cuaternario del Macizo de Ubiña (Asturias-León) y su importancia morfológica. Ería, 4. 3-49. https://doi.org/10.17811/er.0.1983.3-49

Castañón, J.C., Frochoso, M., 1994. El periglaciarismo de la Cordillera Cantábrica. Gómez, A., Simón, M., Salvador, F. (Eds.), Periglaciarismo en la Península Ibérica, Canarias y Baleares. Monografías de la S.E.G., 7, Universidad de Granada, Granada. 75-91.

Castañón, J.C., Frochoso, M., 1998. La alta Montaña Cantábrica: condiciones térmicas y morfodinámicas en los Picos de Europa. Gómez-Ortiz, A., Salvador, F., Schulte, L., García, A., (Eds.), Procesos biofísicos actuales en medios fríos, Universidad de Barcelona, Barcelona. 113-132.

Collignon, B., 1985. Quelques éléments de géologie et d'hydrogéologie. Spelunca, 19. 7-12.

Curras, A., Zamora, L., Redd, J.M., García Soto, E. Ferrero, S., Armengo, X., Mezquina, F., Marqués, M.A., Riera, S., Juliá, R., 2012. Climate change and human impact in central Spain during Roman times: High-resolution multi-proxy of a tuffa lake record (Somolinos, 1280 m.a.s.l). Catena, 89. 31-55. https://doi.org/10.1016/j.catena.2011.09.009

Cvijić, J., 1893. Das karstphänomen Versuch einer morphologischen Monographie. Geographische Abhandlungen, 5. 218-329.

De Waele, J., Plan, L., Audra, P., 2009. Recent developments in surface and subsurface karst geomorphology: An introduction. Geomorphology, $106 \quad$ (1-2). 1-8. https://doi.org/10.1016/j.geomorph.2008.09.023

Fernández, A., Ruiz-Fernández, J., Gallinar, D., García-Hernández, C., 2015. El patrimonio geologico de las hoces del Jucar (La Manchuela-Albacete): Una propuesta de lugar de interes geologico (LIG). Hilario, A., Mendia, M., Monge-Ganuzas, E., Fernandez, J., Belmonte, A., (Eds.), Patrimonio geológico y geoparques, avances de un camino para todos. IGME, Madrid, 55-60.

Flor, G., Flor-Blanco, G., 2013. Geomorfología del litoral oriental de Asturias. Guía de Campo. VII Jornadas de Geomorfología Litoral. Universidad de Oviedo. Oviedo/Uviéu.

Ford, D., Williams, P.D., 2007. Karst hydrogeology and geomorphology. John Wiley \& Sons Ltd., Chichester.

Fornós, J.J., Gràcia, F., Gómez-Pujol, L., 2013. El papel del karst en la morfogénesis costera: el ejemplo de las calas de Mallorca y Menorca. Geotemas, 14. 67-70.

Frochoso, M., González, R., Allende, F., 2013. Pleistocene glacial morphology and timing of Last Glacial Cycle in Cantabrian Mountains (Northern Spain): new chronological data from the Asón Area. Central European Journal of Geoscience, 5. 12-27.

Gallinar, D., Ruiz-Fernández, J., Poblete, M.Á., Fernández, A., García-Hernández, C., Beato, S., Marino, J.L., 2014. Morfología y evolución glaciar en el sector asturiano del Macizo de las Ubiñas. Schnabel, S. y Gómez Gutiérrez, A. (Eds.), Avances de la geomorfología en España 2012-2014. XIII Reunión Nacional de Geomorfología, Sociedad Española de Geomorfología (SEG). Cáceres. 
Garay, P., Morell, I., 1989. Tasas de disolución en regiones kársticas españolas. Durán J.J., López Martínez, J. (Eds.), El karst en España. Monografías de la Sociedad Española de Geomorfología, 4. Madrid. 73-82.

Ginés, J., 2001. El karst litoral en el Levante de Mallorca: una aproximación al conocimiento de su morfogénesis y cronología. Endins: Publicació d'Espeleologia, 24. 143-54.

Gökkaya, E., Gutiérrez, F., Ferk, M., Görüm, T., 2021. Sinkhole development in the Sivas $\begin{array}{lllll}\text { gypsum karst, } & \text { Turkey. } & \text { Geomorphology, } & 386 . & 107746 .\end{array}$ https://doi.org/10.1016/j.geomorph.2021.107746

Gómez Lende, M., 2015. Las cuevas heladas en Picos de Europa: clima, morfologías y dinámica. Tesis Doctoral. Universidad de Valladolid. Valladolid.

González Martín, J.A., González Amuchastegui, M.`J., 2014. Las tobas en España. Editores. SEG, Badajoz.

González-Amuchastegui, Maj., Serrano, E., 2007. Evolución geomorfológica, cambios ambientales e intervención humana durante el Holoceno en la cuenca alta del Ebro: las tobas de los valles del Purón y Molinar. Estudios Geográficos, 263. 527-546.

González-Gutiérrez, R.B., Santos-González, J., Gómez-Villar, A., Alonso-Herrero, E., Garcíade Celis, A., Cano, M., Redondo-Vega, J.M., 2017. Glaciokarst landforms in the Siera de los Grajos, Babia and Luna natural park (Cantabrian Mountains, NW Spain). Acta Carsologica, 46 (2-3). 165-178. https://doi.org/10.3986/ac.v46i2-3.5001

González-Trueba, J. J., 2006. El Macizo Central de los Picos de Europa: geomorfología y sus implicaciones geoecológicas en la alta montaña cantábrica. Tesis Doctoral. Universidad de Cantabria. Santander.

Grupo Espeleológico Polifemo, 2010. Exploración espeleológica en los Joyos de Colines, Macizo de Ubiña (NW. de España). Federación d'Espeleoloxía del Principáu d'Asturies. Oviedo/Uviéu.

Interclub Ubiña del Colectivu Asturianu d'Espeleólogos, 2013. Memoria de exploraciones subterráneas. Federación d'Espeleoloxía del Principáu d'Asturies. Quirós.

Jennings, J.N., 1985. Karst Geomorphology. Blackwell, Londres.

Joly, F., 1997. Glossaire de géomorphologie. Base de données sémiologiques pour la cartographie. Armand Colin, París.

Julián, A., 1994. El karst del pico del Castillo de Acher (Pirineo Occidental, Huesca). Factores condicionantes de su distribución espacial. Geographicalia, 31. 127-141.

Llopis Lladó, N., 1964. Sur la Paleotectónique des Asturies et ses rapports avec la moitié occidentale de la Péninsule Ibérique. Boletín del Instituto de Estudios Asturianos. Suplemento de Ciencias, 10. 101-150.

López-Limia, B. L., López-Bermúdez, F. L., 1985. Tipos de lapiaz en un karst mediterráneo de montaña (sierra de Segura, Jaén). Papeles de Geografía, 10. 21-32.

López-Martínez, J., 1984. Disolución de rocas carbonatadas. Cuantificación del proceso actual de karstificación en el Macizo de la Piedra de San Martin (Pirineo Occidental). Cuadernos de Investigación Geográfica, 10. 127-138.

Lotze, F., 1945. Zur Gliederung der Varisziden der Iberischen Meseta. Geotektonische Forschungen, 6. 78-92.

Maire, R., 1984. Un exemple de karst haut-alpin: le Désert de Platé (Haute-Savoie). Carte géomorphologique au 1/25 000. Karstologia, 3(1). 25-33. 
Maire, R., 1990. La haute montagne calcaire. Karsts, cavités, remplissages, Quaternaire, paléoclimats. Karstologia-Mémories, 3, Association Française de karstologie y Fédération Française de Spéléologie. La Ravoire.

Marcos, A., Pérez Estaún, A., Pulgar, J.A., Bastida, F., Aller, J., García Alcalde, J.L., Sánchez de Posada, L., Rodríguez Fernández, L.R., 1980. Mapa Geológico de España (1:50.000), hoja 77 (La Plaza, Teverga). Instituto Geológico y Minero de España. Segunda serie. Madrid.

Martínez Abad, Í., 2007. Geología del área situada entre Peña Ubiña y el puerto de La Cubilla (Zona Central de la Cordillera Cantábrica). Tesis de Máster. Universidad de Oviedo. Oviedo/Uviéu.

Miotke, F.D., 1968. Karstmorphologische Studien in der glazial-überformten Höhenstufe der "Picos de Europa," Nordspanien. Tesis Doctoral. Selbtverlag der Geografischen Gessellschaft. Hannover.

Moreno, A., Valero, B.L., Jiménez, M., Domínguez, M.J., Mata, M.P., Navas, A., González, P., Stoll, H., Farias, P., Morellón, M., Corella, J.P., Rico, M., 2010. The last deglaciation in the Picos de Europa National Park (Cantabrian Mountains, Northern Spain). Journal of Quaternary Science, 25 (7). 1076-1091. https://doi.org/10.1002/jqs. 1265

Muñoz Jiménez, J., 1980. Morfología estructural y glaciarismo en la Cordillera Cantábrica: el relieve del Sinclinal de Saliencia (Asturias-León). Ería, 1. 35-65. http://dx.doi.org/10.17811/er.0.1980.35-65

Muñoz Jiménez, J., 1982. Geografía Física. El relieve, el clima y las aguas. Quirós, F. (Ed.), Geografía de Asturias. Tomo 1. Ayalga Ediciones. Salinas.

Nicod, J., 1972. Pays et paysages du calcaire calcaire. Presses Universitaires de France, París.

Obermaier, H., 1914. Estudio de los glaciares de los Picos de Europa. Trabajos del Museo Nacional de Ciencias Naturales, Madrid, Serie Geológica, 9. 9-41.

Ordóñez, S., González Martín, J.A., Del Cura, M.G., Pedley, H.M., 2005. Temperate and semiarid tufas in the Pleistocene to Recent fluvial barrage system in the Mediterranean area: The Ruidera Lakes Natural Park (Central Spain). Geomorphology, 69 (1-4). 332-350. https://doi.org/10.1016/j.geomorph.2005.02.002

Parise, M., 2011. Surface and subsurface karst geomorphology in the Murge (Apulia, southern Italy). Acta Carsologica, 40 (1). 79-93. https://doi.org/10.3986/ac.v40i1.30

Pellitero, R., 2012. Geomorfología, paleoambiente cuaternario y geodiversidad en el Macizo de Fuentes Carrionas-Montaña Palentina. Tesis Doctoral. Universidad de Valladolid. Valladolid.

Pellitero, R., 2013. Evolución finicuaternaria del glaciarismo en el macizo de Fuentes Carrionas (Cordillera Cantábrica), propuesta cronológica y paleoambiental. Cuaternario $y$ Geomorfología, (1-2). 71-90.

Pisabarro, A., Pellitero, R., Serrano, E., Gómez Lende, M., González Trueba, J.J., 2017. Ground temperatures, landforms and processes in an Atlantic mountain. Cantabrian Mountains (Northern Spain). Catena, 149. 623-636. https://doi.org/10.1016/j.catena.2016.07.051

Puch, C., 1998. Grandes simas y cuevas de España. Espeleo Club de Gràcia (Ed.). Barcelona.

Puerta Elorza, E., 2000. Asemeyu en los Joyos de Cueva Palacios (Macizo de Ubiña). III Congreso Espeleológico Internacional sobre Picos de Europa y VI Congreso Asturiano de Espeleología.

Rodríguez Pérez, C., 1995. Estudio geomorfológico del Puerto de San Isidro. Ería, 36, 63-87. https://doi.org/10.17811/er.0.1995.63-87 
Rodríguez Pérez, C., 1998. Las formas de relieve y la evolución geomorfológica de la sierra de Sobia (área central de Asturias). Ería, 46. 131-147. https://doi.org/10.17811/er.0.1998.131147

Rodríguez Pérez, C., 2009. Geomorfología de la montaña astur-leonesa entre los puertos de Ventana y Somiedo. Tesis Doctoral. Universidad de Oviedo. Oviedo/Uviéu.

Rodríguez Pérez, C., 2015. El relieve de la Montaña Central Asturiana: La Sierra de Sobia y el Macizo de Somiedo. Real Instituto de Estudios Asturianos, Oviedo/Uviéu.

Rodríguez Pevida, A.R., de la Fuente, J.C., González Suárez, J.J. 1982. Pozu La Carba. Espeleología Asturiana, 6. 1-10.

Rodríguez-Rodríguez, L. Jiménez, M., Domínguez, M.J., Rinterknecht, V., Pallàs, R., Bourlès, D., 2016. Chronology of glaciations in the Cantabrian Mountains (NW Iberia) during the Last Glacial Cycle based on in situ-produced 10Be. Quaternary Science Reviews, 138. 3148. https://doi.org/10.1016/j.quascirev.2016.02.027

Rodríguez-Rodríguez, L., Domínguez-Cuesta, M.J., Rinterknecht, V., Jiménez-Sánchez, M., González-Lemos, S., Léanni, L., Sanjurjo, J., Ballesteros, D., Valenzuela, P., Llana-Fúnez, S., ASTER Team., 2018. Constraining the age of superimposed glacial records in mountain environments with multiple dating methods (Cantabrian Mountains, Iberian Peninsula). Quaternary Science $\quad$ Reviews, $195 . \quad 215-231$. https://doi.org/10.1016/j.quascirev.2018.07.025

Rodríguez-Rodríguez, L., Jiménez-Sánchez, M., Domínguez-Cuesta, M.J., Rinterknecht, V., Pallàs, R., ASTER TEAM, 2017. Timing of last deglaciation in the Cantabrian Mountains (Iberian Peninsula; North Atlantic Region) based on in situ-produced 10Be exposure dating. Quaternary Science Reviews, 171. 166-181. https://doi.org/10.1016/j.quascirev.2017.07.012

Romero, D., 1984. Tipología de formas kársticas y relaciones morfoestructurales en la marina oriental asturiana. Ería, 7. 119-134. https://doi.org/10.17811/er.0.1984.119-132

Rossi, C., 2004. Picos de Europa, Spain. En: Gunn, J., (Ed.), Encyclopaedia of Caves and Karst Science, pp. 582-585. Fitzroy Dearborn, New York-London.

Ruiz-Fernández J., Poblete, M.Á., 2012. Las simas del macizo Occidental de los Picos de Europa: disposición estructural, depósitos asociados y características del drenaje. Investigaciones Geográficas, 57. 205-223. https://doi.org/10.14198/INGEO2012.57.10

Ruiz-Fernández, J., 2011. Geomorphological map of an Atlantic mid-height mountain area: the Juan Robre and Jana Ridge (Cantabrian Range, Northwest Spain). Journal of Maps, 7 (1). 260-272. https://doi.org/10.4113/jom.2011.1173

Ruiz-Fernández, J., 2013. Las formas de modelado glaciar, periglaciar y fluviotorrencial del Macizo Occidental de los Picos de Europa (Cordillera Cantábrica). Tesis Doctoral. Universidad de Oviedo. Oviedo/Uviéu.

Ruiz-Fernández, J., García-Hernández, C., Fernández Fernández, A., 2019. La organización altitudinal de las formas kársticas del Macizo Occidental de los Picos de Europa (Montañas Cantábricas) y su interrelación con el glaciarismo Cuaternario y la morfodinámica periglaciar. Cadernos do Laboratorio Xeolóxico de Laxe, 41. 153-200. https://doi.org/10.17979/cadlaxe.2019.41.0.5822

Ruiz-Fernández, J., González-Díaz, B., Gallinar Cañedo, D., García-Hernández, C., 2022. The glaciers of the Central-Western Asturian Mountains. En: Oliva, M., Palacios, D., Fernández-Fernández, J.M. (Eds.), Iberia, Land of Glaciers. How the mountains were shaped by glaciers, pp. 265-288. Elsevier, Amsterdam - Oxford - Cambridge. https://doi.org/10.1016/B978-0-12-821941-6.00013-X. 
Ruiz-Fernández, J., Oliva, M., Cruces, A., Lopes, V., Freitas, M.C., Andrade, C., GarcíaHernández, C., López-Sáez, J.A., Geraldes, M., 2016. Environmental evolution in the Picos de Europa (Cantabrian Mountains, SW Europe) since the Last Glaciation. Quaternary Science Reviews, 138. 87-104. https://doi.org/10.1016/j.quascirev.2016.03.002

Ruiz-Fernández, J., Oliva, M., Hrbáček, F., Vieira, G., García-Hernández, C., 2017. Soil temperatures in an Atlantic high mountain environment: The Forcadona buried ice patch (Picos de Europa, NW Spain). Catena, 149 (2). 637-647. https://doi.org/10.1016/j.catena.2016.06.037

Ruiz-Fernández, J., Poblete, M.Á., García-Hernández, C., 2014. Características morfoclimáticas y procesos y formas periglaciares actuales en el Macizo Occidental de los Picos de Europa (Cordillera Cantábrica). Gómez-Ortiz A., Salvador F., Oliva M., Salvà, M., (Eds.), Avances, métodos y técnicas en el estudio del periglaciarismo, Universidad de Barcelona, Barcelona. 91-103.

Ruiz-Fernández, J., Serrano, E., 2011. El modelado kárstico en el Macizo del Cornión. En: González Trueba, J.J., Serrano, E. (Eds.): Geomorfología del Macizo Occidental del Parque Nacional Picos de Europa. OAPN, Ministerio de Medio Ambiente, Madrid.

Sáez Hernández, J.M., Gómez de Benito, L., 1988. Evolución morfológica del Monte Sueve. Ería, 15. 80-84. https://doi.org/10.17811/er.0.1988.80-84

Salazar, Á., Mata, M.P., Valero-Garcés, B., Rico, M., Moreno, A., Rubio, F.M., Ibarra, P., 2016. El semipolje de La Estiva (Valle de Pineta, Pirineo oscense): origen, morfoestructura y procesos recientes en una depresión kárstica compleja. Durán Valsero, J. J., Montes, M., Robador, A., Salazar, A. (Eds.), Comprendiendo el relieve: del pasado al futuro. Instituto Geológico y Minero de España. 687-694.

Santos Alonso, R., Marquínez García, J., 2005. Las formas del lapiaz en el Macizo del Cornión, Picos de Europa. Cuaternario y Geomorfología, 19 (1-2). 35-47.

Senior, K. J., 1987. Geology and speleogenesis of the M2 Cave System, Western Massif, Picos de Europa, Northern Spain. Cave Science, 14 (3). 93-103.

Serrano, E., González-Trueba, J. J., 2004. Morfodinámica periglaciar en el grupo Peña Vieja (Macizo Central de los Picos de Europa - Cantabria). Cuaternario y Geomorfología, 18 (34). 73-88.

Serrano, E., González-Trueba, J.J., González-García, M., 2012. Mountain glaciation and paleoclimate reconstruction in the Picos de Europa (Iberian Peninsula, SW Europe). Quaternary Research, 78. 303-314. https://doi.org/10.1016/j.yqres.2012.05.016

Serrano, E., González-Trueba, J.J., Pellitero, R., González-García, M., Gómez-Lende, M., 2013. Quaternary glacial evolution in the Cantabrian Mountains (Northern Spain). Geomorphology, 196. 65-82. https://doi.org/10.1016/j.geomorph.2012.05.001

Smart, P.L., 1984. The geology, geomorphology and speleogenesis of the Eastern Massif, Picos de Europa, Spain. Cave Science, 11 (4). 238-245.

Smart, P.L., 1986. Origin and development of glacio-karst closed depressions in the Picos de Europa, Spain. Zeitschrift für Geomorphologie N. F., 30. 423-443.

Suárez Uriarte, P., 1922. Cueva-Melluque. Impresiones de una excursión. Renacimiento, L, 10. 109-111.

Sweeting, M.M., 1972. Karst landforms. McMilan Press, Londres.

Sweeting, M.M., 2012. Karst in China: its geomorphology and environment. (Vol. 15). Springer Science \& Business Media.

Truyols, J., Arbizu, M., García Alcalde, J.L., García López, S., Martínez Chacón, M.L., Méndez Bedia, I., Méndez Fernández, C., Menéndez, J.R., Sánchez de Posada, L. C., Soto, F., 
Truyols Massoni, M., Villa, E., Marcos, A., Pérez Estaún, A., Pulgar, J.A., Bastida, F., Aller, J., Lorenzo, P., Rodríguez Fernández, L.R., 1982. Memoria del Mapa Geológico de España (1:50.000), hoja 77 (La Plaza, Teverga). Instituto Geológico y Minero de España. Segunda serie. Madrid.

Veress, M., 2010. Karst environments: karren formation in high mountains. Springer Science \& Business Media.

Verheyden, S., Faverjon, M., Borchers, N., Charavel R., Cholin, A., Sánchez, N., Scipioni, M., Gillet, R. y Delaby S., 2007. La sima Thesaurus Fragilis. Exploraciones 2006 y 2007. Vega Huerta, macizo de Cornión, Picos de Europa. Subterránea, 28. 24-31.

White, W.B. 1984. Rate processes: Chemical kinetics and karst landform development. LaFleur, R.G. (Ed.), Groundwater as a Geomorphic Agent, Allen and Unwin Ltd., Boston. 227-248.

White, W.B., 1988. Geomorphology and hydrology of karst terrains, Oxford University Press, New York - Oxford.

Woodward, J.C., Lewin, J., 2009. Karst Geomorphology and Environmental Change. In The Physical Geography of the Mediterranean. Oxford University Press. 287-317. 